\title{
The effectiveness of a multifocal training to improve the treatment of community-acquired MRSA skin and soft tissue infections
}

\author{
Aaron Santmyire \\ West Virginia University
}

Follow this and additional works at: https://researchrepository.wvu.edu/etd

\footnotetext{
Recommended Citation

Santmyire, Aaron, "The effectiveness of a multifocal training to improve the treatment of communityacquired MRSA skin and soft tissue infections" (2012). Graduate Theses, Dissertations, and Problem Reports. 521.

https://researchrepository.wvu.edu/etd/521

This Dissertation is protected by copyright and/or related rights. It has been brought to you by the The Research Repository @ WVU with permission from the rights-holder(s). You are free to use this Dissertation in any way that is permitted by the copyright and related rights legislation that applies to your use. For other uses you must obtain permission from the rights-holder(s) directly, unless additional rights are indicated by a Creative Commons license in the record and/ or on the work itself. This Dissertation has been accepted for inclusion in WVU Graduate Theses, Dissertations, and Problem Reports collection by an authorized administrator of The Research Repository @ WVU. For more information, please contact researchrepository@mail.wvu.edu.
} 
The effectiveness of a multifocal training to improve the treatment of community-acquired MRSA skin and soft tissue infections

Aaron Santmyire, MSN, FNP

Doctoral Research Project submitted to the School of Nursing at West Virginia University in partial fulfillment of the requirements

for the degree of

Doctor

of

Nursing Practice

Alvita Nathaniel, Ph.D., FNP-BC, Chair

Janet Crigler, MT (ASCP), CIC

Michael Levitas, M.D

Department of Nursing

Morgantown, West Virginia

2012

Key words: community acquired MRSA (CA-MRSA), skin and soft tissue infections (SSTIs), antibiotic resistance 


\title{
Abstract \\ The effectiveness of a multifocal training to improve the treatment of community- acquired MRSA skin and soft tissue infections
}

\author{
Aaron Santmyire \\ Practitioners and researchers have documented an increase in community-acquired \\ methicillin resistant staphylococcus aureus (CA-MRSA) skin and soft tissue infections \\ (SSTIs). This increase is causing stress and concern for the individuals infected and the \\ families of those infected. The impact of a practitioner based multifocal training has not \\ been clearly established. The purpose of this capstone project was to determine the effect \\ of a multifocal training on CA-MRSA SSTIs that educated primary care practitioners \\ about treatment guidelines, Marion County, WV susceptibility data, I\&D technique, and \\ a patient education tool versus common treatment practices to increase practitioner's \\ knowledge and utilization of evidence based guidelines in the treatment of CA-MRSA \\ SSTIs. Multifocal trainings educated practitioners concerning CA -MRSA SSTIs in \\ Marion County, West Virginia.
}




\section{Contents}

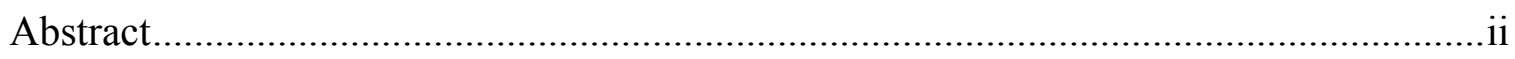

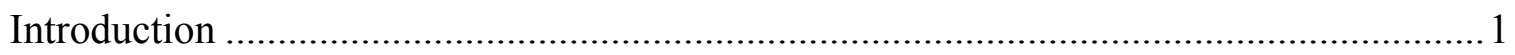

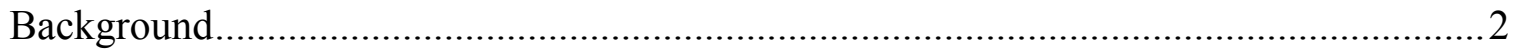

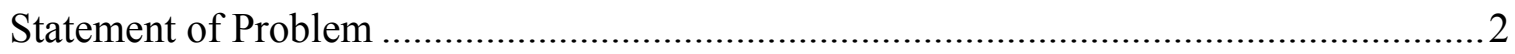

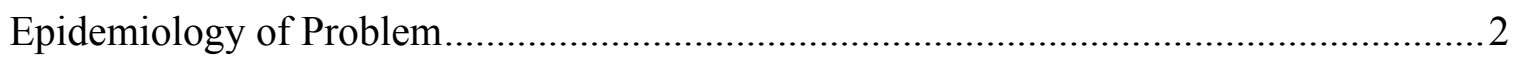

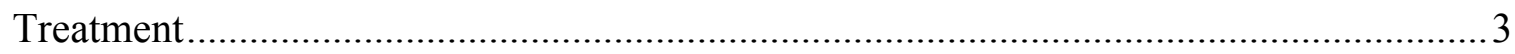

Antibiotic Resistance .............................................................................................

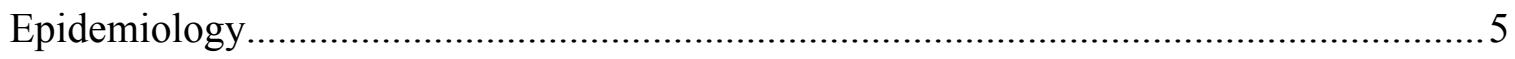

Description of Population...................................................................................... 6

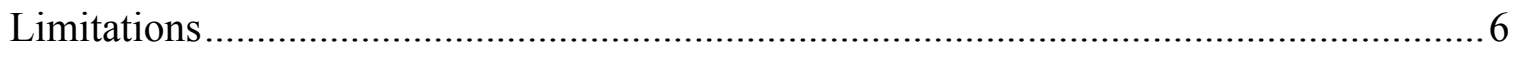

Demographics and Unique Factors Affecting Care.......................................................

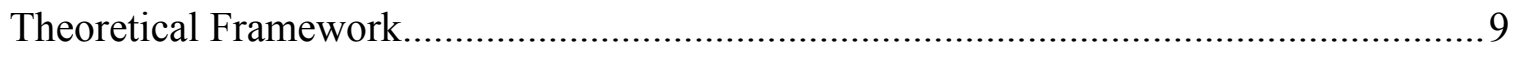

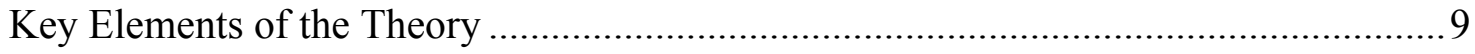

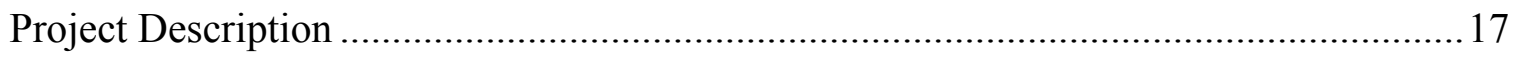

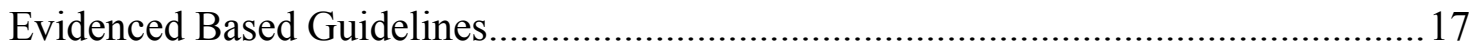

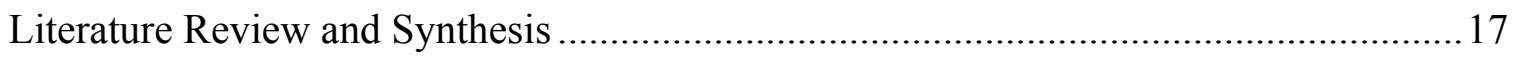

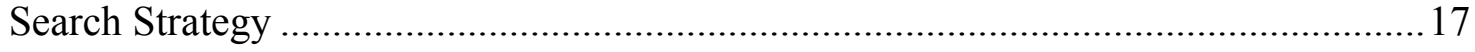

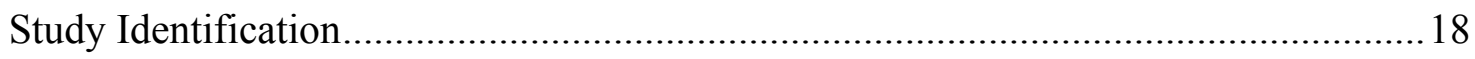

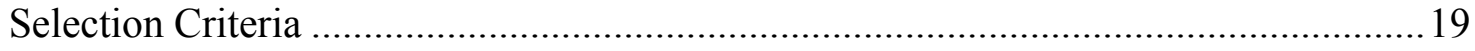

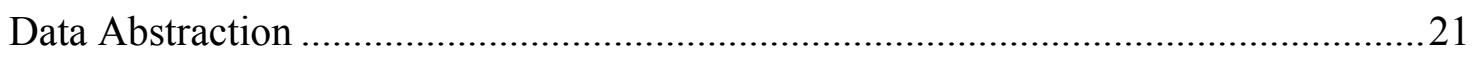

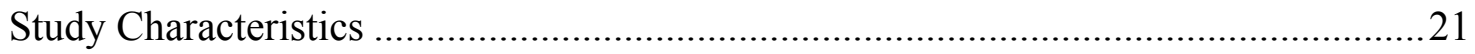

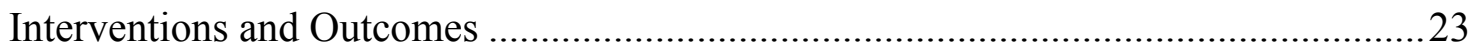

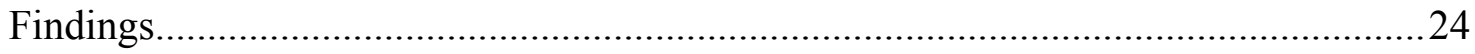

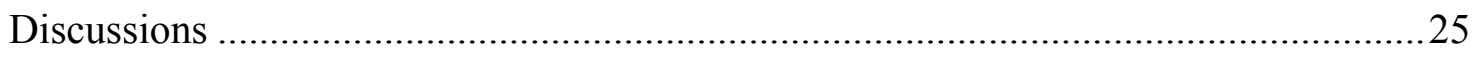

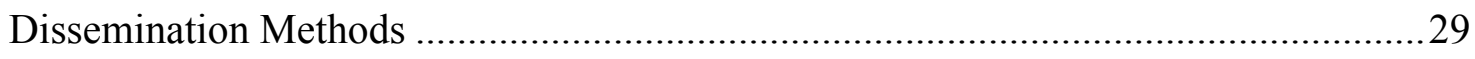

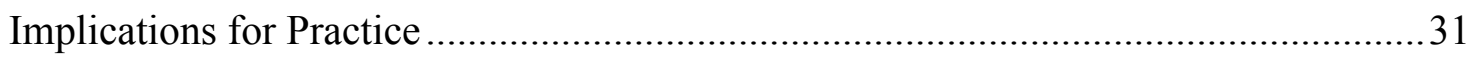

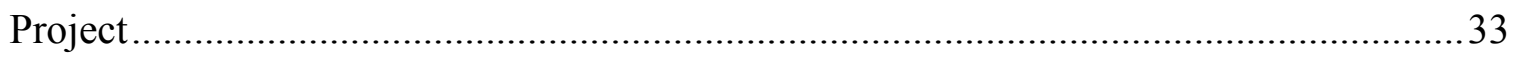

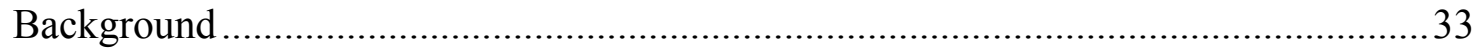

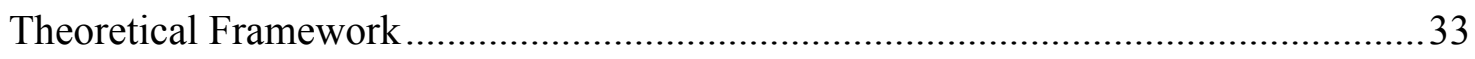

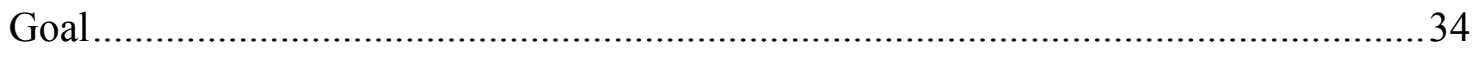

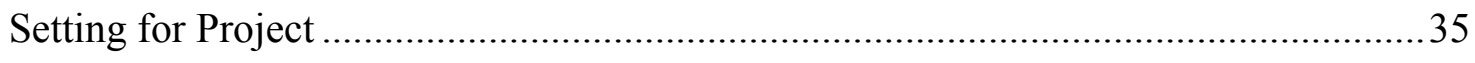




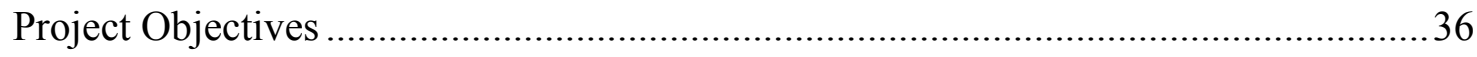

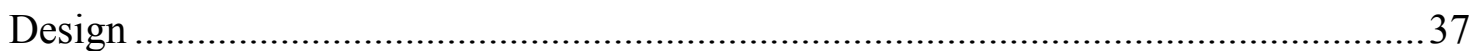

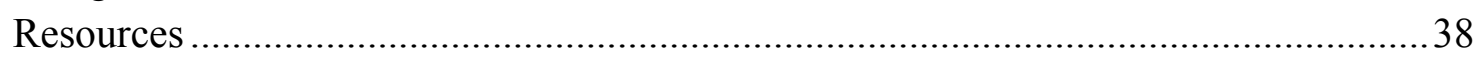

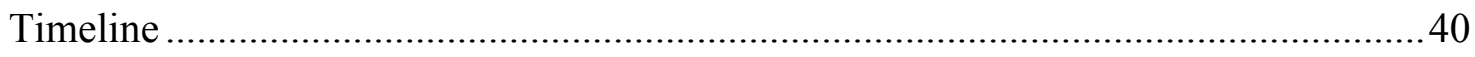

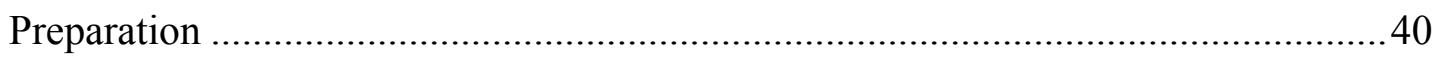

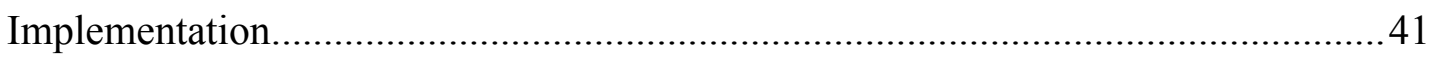

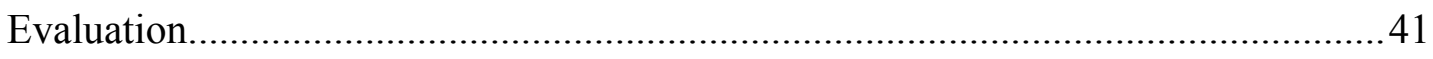

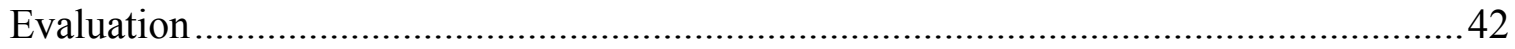

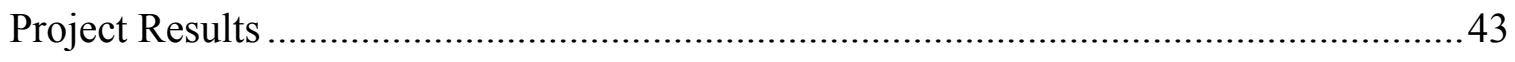

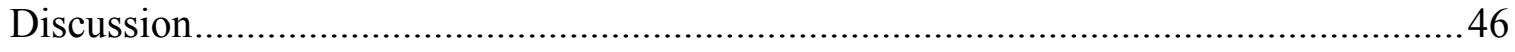

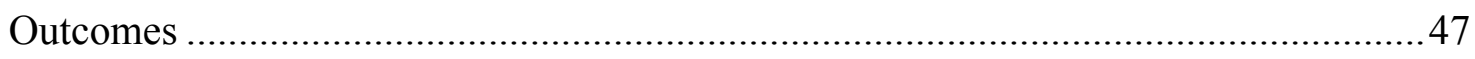

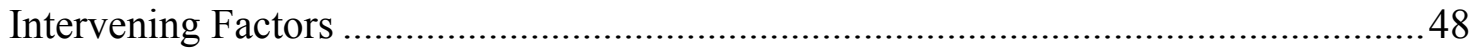

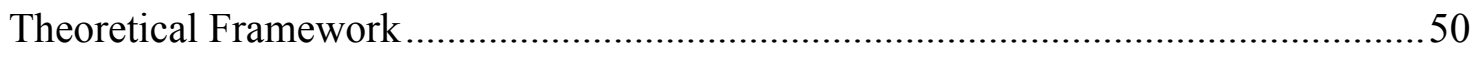

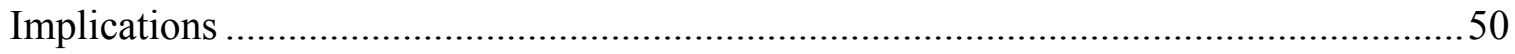

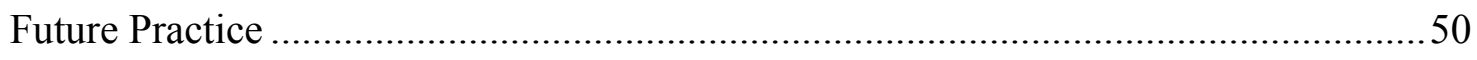

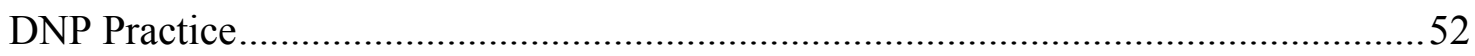

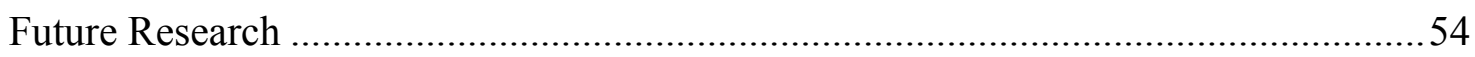

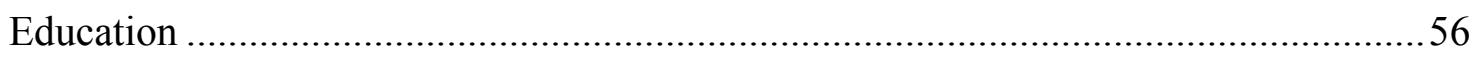

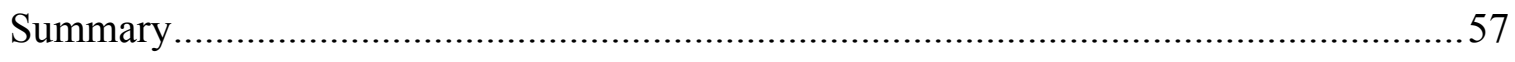

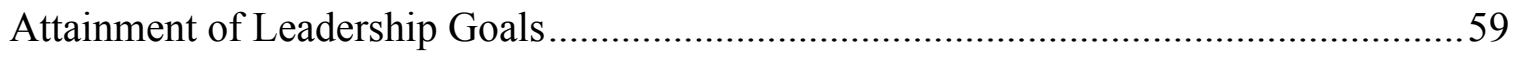

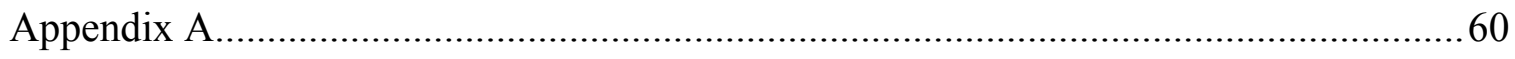

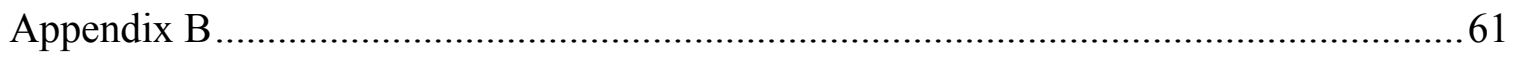

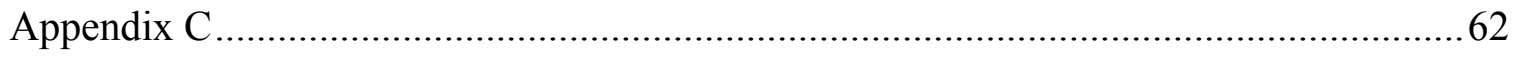

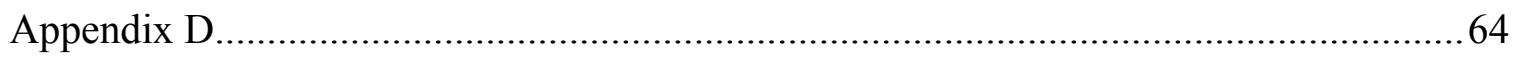

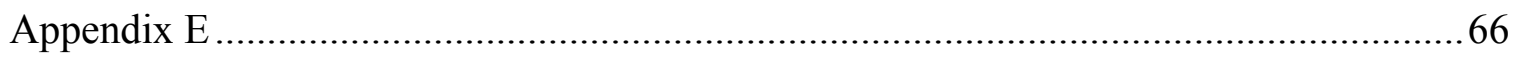

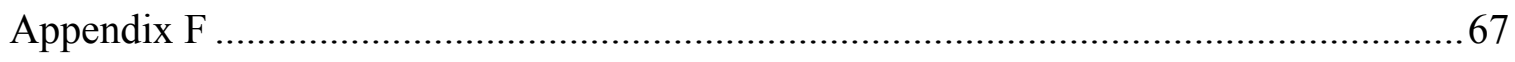

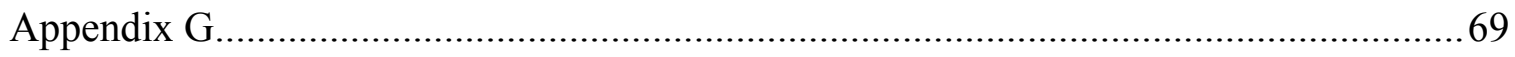

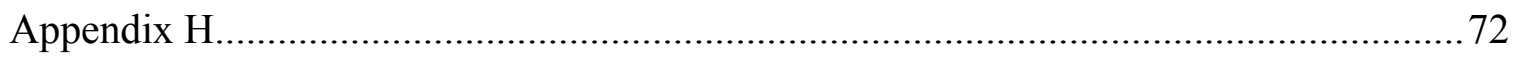

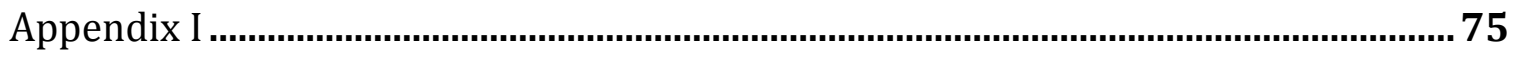

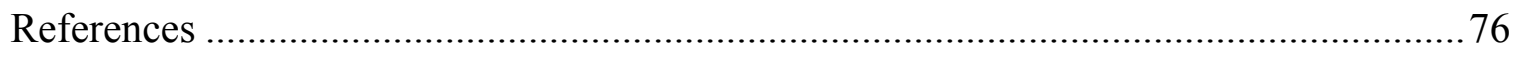




\section{Introduction}

Treatment of patients with community-acquired methicillin resistant staphylococcus aureus (CA-MRSA) skin and soft tissue infections (SSTIs) is a major challenge and concern in the global health care community. These infections are rapidly becoming more prevalent (McCaig et al., 2006) and prevention of further antibiotic resistance is of paramount importance (World Health Organization [WHO], 2010). Primary health care providers need to know the most effective method of treatment and control of CA-MRSA SSTIs in the pediatric population to achieve resolution of infection, prevent adverse health outcomes, and limit spread of the infection.

It is imperative that primary care practitioners know and implement current practice guidelines for the treatment of CA-MRSA SSTIs. Despite current recommendations for incision and drainage (I\&D) to be the primary treatment for uncomplicated CA-MRSA SSTIs (Gorwitz, 2008; Liu et al., 2010), substantial practice variation in use of I\&D and antibiotic prescription persist (Baumann, 2011; Hersh et al., 2009). Increasing consistency and use of evidence-based care is important to both prevent inadequate treatment and improve patient outcomes. Appropriate antibiotic prescribing practices are particularly important to help reduce the spread of antibiotic resistance (Gorwitz, 2008). Evidence-based practice can potentially both improve patient outcomes and reduce the risk of adverse outcomes. The purpose of this paper is to describe the implementation and evaluation of a practice change concerning the treatment of CAMRSA SSTIs. Implications and recommendations for primary care practice are presented. 


\section{Background and Significance of the Proposed Intervention \\ Statement of the Problem}

The prevalence of CA-MRSA SSTIs has been well documented, yet evidence suggests practitioners are not following clinical practice guidelines in treatment of these infections. Treatment changes are paramount in the fight against CA-MRSA and practitioners must follow the clinical practice guidelines and begin to utilize I\&D more frequently and antibiotics only when warranted.

\section{Epidemiology of the Problem}

Although antibiotic resistant bacteria are not a new phenomenon, the World Health Organization ([WHO]; 2010) has identified the development of antibiotic resistance as one of the most significant public health threats of the $21^{\text {st }}$ century. Methicillin-resistant staphylococcus aureus (MRSA) is one of these antibiotic resistant bacteria, prevalent in the community, contagious, difficult to treat and eradicate, and at times, lethal (Newland \& Kearns, 2008). In the 1960s, the first occurrence of MRSA was observed in the hospital setting (Barrett, McGhee, \& Finland, 1968); hence the label hospital-acquired methicillin-resistant staphylococcus aureus (HA-MRSA). Risk factors associated with HA-MRSA include prolonged hospitalization, surgical intervention, dialysis, close contact with other patients with MRSA, implanted medical devices, and admission into intensive care or burn units (Newland \& Kearns).

Until the 1980s, MRSA remained a major problem in the hospital but had not yet become a major pathogen in the community (Fergie \& Purcell, 2001). In the 1980s, the 
first individual case of MRSA in the community without the risk factors of HA-MRSA was observed. This type of MRSA became known as community-acquired methicillinresistant staphylococcus aureus (CA-MRSA). Herold et al. (1998) reported an increasing trend in the 1990s in SSTIs caused by CA-MRSA in patients with none of the known risk factors previously associated with HA-MRSA. CA-MRSA has become a major pathogen in the community, specifically affecting the pediatric population in SSTIs (Centers for Disease Control [CDC], 2010). CA-MRSA is a common and serious problem, usually involving skin, especially among children (Fridkin et al., 2005). Most CA-MRSA infections occur in infants, children, and teenagers (CDC, 2010). In this population, $80 \%$ of the CA-MRSA infections present as SSTIs. Community onset SSTIs account for the majority of MRSA infections in children (Gorwitz, 2008). Children who are enrolled in childcare centers, athletes, tattoo recipients, and neonates are at increased risk for CA-MRSA SSTIs. Additional risk factors include age ( $<2$ years), minority race or ethnicity, and low socioeconomic status (CDC, 2010).

\section{Treatment}

Worldwide, clinicians and researchers are addressing the health care challenge of CA-MRSA SSTIs. A key concern associated with treatment of CA-MRSA STTIs is that staphylococcus aureus will continue to develop resistance to these remaining antibiotics and further limit treatment options. A focus of research has been to identify the most efficacious way of treating CA-MRSA SSTIs that will also be the least likely to create further antibiotic resistance. A parallel concern has been to avoid unnecessary treatment with antibiotics when clinical situations warrant. While there are significant variations in 
regional susceptibility patterns that influence treatment selected, antibiotics to which CAMRSA is currently susceptible include vancomycin, clindamycin, trimethoprimsulfamethoxazole, doxycycline and minocycline, daptomycin, and linezolid (Liu etal., 2011). It must be noted that only clindamycin, trimethoprim-sulfamethoxazole, doxycycline (for children 9 years or older), and minocycline (for children 9 years or older), are used for treating the outpatient pediatric CA-MRSA SSTI. When empiric treatment is warranted, practitioners can use local antibiograms, the compilation of individual antimicrobial tests, to know the susceptibility data when choosing an empiric antibiotic.

\section{Antibiotic resistance}

In 1928, Professor Alexander Fleming recognized that a mold was inhibiting the growth of bacteria (NIH, 2009). He remarked that this mold was able to repel and destroy other bacteria. Fleming's discovery effectively ushered in the era of antibiotics. For over 70 years, antibiotics have been used to treat innumerable infections and prolong countless lives. However, after many decades of use, and over use, of antibiotics, bacteria have developed resistance to them (NIH, 2009). After being exposed to antibiotics, the bacteria have altered their genetic structure so that they are no longer susceptible to certain types of antibiotics.

Another important part of the etiology of antibiotic resistance is the process of selectively eliminating, intentionally or unintentionally, bacteria from the body. Bacteria normally colonize the skin of humans. When an individual's skin is intact, these bacteria are not harmful and are believed to be in some ways beneficial. However, when 
individuals take or receive antibiotics, these medications theoretically kill or inhibit the growth of all bacteria that are susceptible to the antibiotic $(\mathrm{NIH}, 2009)$. The bacteria that are left on the skin are the ones that are resistant to the antibiotic, and are then freely able to multiple and become the dominant bacteria.

The problem arises the next time the integrity of the skin is broken or the individual has another infection, because these bacteria are no longer susceptible or are developing resistance to that type of antibiotic. A different type of antibiotic is needed to treat the bacterial infection. After continual cycles of taking antibiotics, it becomes increasingly difficult to find antibiotics that are effective against the bacteria that remain. It is interesting to note that several of the antibiotics used to treat CA-MRSA, such as trimethoprim-sulfamethoxazole, are older medications that had fallen out of favor of the medical community for treatment of infections. It is these medications that had not been extensively used for some time, that are now at times the first line defense against CAMRSA SSTIs (Liu et al., 2011).

\section{Epidemiology}

Although there is evidence that SSTIs are rapidly increasing across the United States, the exact incidence and prevalence of non-invasive MRSA and CA-MRSA are not known (CDC, 2010). A major barrier to measuring the incidence and prevalence data is that MRSA is not a nationally reportable disease. In the literature, incidence and prevalence data are often taken from individual studies and standardized for the United States. One such study that is accepted by the Centers for Disease Control (CDC) as representative of prevalence for the United States, used the National Ambulatory Medical 
Care Surveys (NAMCS) and National Hospital Ambulatory Medical Care Surveys (NHAMCS) to estimate the prevalence of CA-MRSA SSTIs (McCaig et al., 2006). These researchers estimated that in 2005, there were 14 million outpatient visits that were suspected staphylococcus aureus and SSTIs.

Because neither CA-MRSA nor MRSA are reportable to the CDC, neither are included in the Morbidity and Mortality Weekly Report (MMWR) published by the CDC (2008). Therefore, national and local morbidity and mortality statistics are not collected. According to the CDC (2011), the most accurate, currently available assessment of morbidity and mortality associated with CA-MRSA is a study conducted by Klevens et al (2008). From July 2004 through December 2005, these researchers conducted a population-based surveillance for invasive MRSA in nine different sites across the United States. The researchers standardized the results from their surveillance and derived a standardized mortality rate of 6.3 per 100,000 for all cases of MRSA and 0.5 per 100,000 for CA-MRSA.

\section{Description of the Population}

The target population was practitioners and the patients and families who develop or are affected by CA-MRSA SSTIs in Marion County, West Virginia.

\section{Limitations}

The population of interest was limited to the practitioners, families, and the pediatric population who live in Marion County, West Virginia. There were 23,652 households in Marion County in 2000 (US Census, 2009). The pediatric population 
consists of 11,285 children. Of these 11,285 children, 3,176 of these children were under the age of 5 years.

Marion County has over 120 physicians, six family nurse practitioners, and 15 pharmacists who work within the county. These practitioners vary in ethnicity and educational background. For the purpose of this capstone project, medical doctors, doctors of osteopathic medicine, physician assistants, nurse practitioners, and pharmacists were targeted.

While no specific demographic data for the practitioner population was available, there was demographic data available for the general population of Marion County. The ethnic make-up of the population of Marion County is $94.5 \%$ White, $3.5 \%$ Black, and 1.1\% Latino or Hispanic (US Census, 2009). English is the primary language spoken at home by $97.3 \%$ of the population, and Spanish is the second most spoken language at $1.3 \%$ (US Census, 2009). The US Census (2009) also recorded the gender stratification as $51.9 \%$ female and $48.1 \%$ male.

\section{Demographics and Unique Factors Affecting Care}

Marion County is located in north central West Virginia. The county seat is Fairmont, which is located 20 miles from Morgantown, West Virginia. The total population of Marion County is 56,706 (U.S Census, 2009). The median age is 39.9 years of age. The population is diversified with part of the population living in rural conditions and the other part of the population living in small towns and cities. The average annual household income is $\$ 36,086$ (U.S. Census). Of those who live in the 
county, $18.8 \%$ are living below the poverty line. This is higher than the rest of West Virginia, where $17.6 \%$ are living in poverty (U.S. Census). In the past and present, coal mining and natural gas have been and continue to be the driving force of the economy. Two other large growing employers are Fairmont State University and Fairmont General Hospital. Quality medical care is available and the largest provider in the county is Fairmont General, which is a large community non-profit hospital.

Although CA-MRSA SSTIs can affect the whole community, most CA-MRSA infections occur in infants, children, and teenagers (CDC, 2010). In this population, 80\% of the CA-MRSA infections present as SSTIs. Children enrolled in childcare centers, athletes, tattoo recipients, and neonates have been identified by epidemiologists as at increased risk for CA-MRSA SSTIs (Baker, 2007). The CDC has also identified that children less than two years of age, children of ethnic minority groups, and children of parents of low socio-economic status are at increased risk (2010).

Low socio-economic status is a barrier to health care access and a risk factor for CA-MRSA. In their research on CA-MRSA SSTIs in the pediatric population, Doung et al. (2010) remarked that parents of low socio-economic status often use the emergency room as the source of primary care for their children. They listed lack of insurance and the lack of a family doctor as two major reasons for this. In Marion County in 2000, eight percent of those less than 18 years of age had no health insurance coverage. Quality health care is available in Marion County, but without health insurance or finances to pay for it, it is not accessed effectively. With the number of West Virginians living below the 
poverty level, the children of Marion County are at increased risk for CA-MRSA SSTIs because of their socio-economic status.

The educational level of those living in Marion County also places the population at increased risk for communicable diseases such as CA-MRSA. Of the adult population, $79.5 \%$ of the population are high school graduates and $16 \%$ hold a bachelor's degree or higher (US Census, 2009). Nineteen percent of Marion County adults have a level 1 literacy proficiency (the lowest level on a scale of 1-5) (West Virginia Department of Education, 2010). Low literacy is linked to adverse health outcomes such as decreased health knowledge and less than adequate use of preventive health services (Agency for Healthcare and Quality, 2004). The low literacy level and poverty also negatively affect health literacy. In Marion County, these specific negative factors create cultural barriers for health education interventions and require that adaptations be made to accommodate these barriers.

\section{Theoretical Framework}

Rogers's theory of Diffusion of Innovations was used to guide this Doctor of Nursing Practice capstone project. The capstone project had as its practice question: what is the effect of a multifocal training on CA-MRSA SSTIs that educates primary care practitioners about treatment guidelines, Marion County, WV susceptibility data, I\&D technique, and a patient education tool versus common treatment practices to increase practitioner's knowledge and utilization of evidence based guidelines in the treatment of CA-MRSA SSTI? 


\section{Key Elements of Diffusion Framework}

Everett Rogers developed the theory of Diffusion of Innovations to explain and describe social change (2003). In early investigations, Rogers studied the diffusion of agricultural innovations and specifically why some farmers adopted new technologies and advancements, and others did not. Rogers sought to explain the why, how, and speed or rate at which new ideas and practices were spread across the agricultural community (Rogers, 2003). To advance the theory, Rogers was able to test it cross-culturally and was able to confirm that the theory was applicable in other cultural settings and was not unique to the United States. Rogers continued drawing conclusions and identified regularities concerning diffusion that are found across cultures, innovations, and the social groups that adopt innovations.

Rogers identified four main elements of the diffusion process as innovation, communication channels, time, and social systems (Rogers, 2003).

1. Innovation- an idea, practice, or object that is perceived as new by an individual.

2. Communication channels- the means by which individuals or groups relay information for the purpose of reaching a mutual understanding.

3. Time- a system of measurement that quantifies the rate of passing through an innovation process and the speed of adoption.

4. Social system- a set of interrelated units that are involved in joint problem solving to accomplish a goal. 
The innovation for this capstone project had several components. These components were the CDC guidelines on treatment of CA-MRSA SSTIs (Appendix D), Marion County susceptibility data for 2011 (Appendix E), I\&D instructional video, and a patient education tool (Appendix C). It was hypothesized that the one or all of the components may be new to the practitioners. Those practitioners who do not use the guidelines in treatment of CA-MRSA SSTIs considered the components an innovation.

The communication channels for this project were diverse and their utilization depended upon the stage of the project. This project utilized both oral and written communication to transmit the innovation. In the initial development stages, email, telephone calls, and interviews were used to solidify feasibility and acceptability of the project. In the educational setting, oral and written communication were used and also included technological mediums such as the website (Appendix B) and Powerpoint. Communication not only occurred in a didactic form, but was also engaging and conversational. Daly et al. found that physicians who were engaged in discussion on the guidelines and barriers were more apt to accept the innovation (2011).

The element of time was also integrated into the capstone project. Hader et al. (2007) noted in their qualitative study on practice change in physicians that acceptance of an innovation is a complex process and not a single decision point. Hader emphasized that the rate of this complex process varies. Time was used as a measure of whether the multifocal training was effective or not. An example of this was the follow-up evaluation, which was sent to practitioners who attended the training. The practitioners were asked 
questions about whether they had treated patients with CA-MRSA SSTIs and/or used the guidelines or website during the follow-up period.

The element of social systems also guided this project. The culture of practitioners has different levels of perceived standing or hierarchy. The question of whether medical doctors, who are perceived as on the upper level of the hierarchy, would be accepting of instruction or introduction of the innovation by a mid-level nurse practitioner was important and may have affected outcomes. Therefore, champions from the medical community were sought out for their expertise, insight, direction, and influence.

Rogers expanded upon the elements of the diffusion process by delineating five stages that occur in the adoption process of an innovation. These fives stages are knowledge, persuasion, decision, implementation, and confirmation (Rogers, 2003).

1. Knowledge- the point at which an individual becomes aware of an innovation and how it functions. The three stages of knowledge are awareness, application knowledge, and principle knowledge.

2. Persuasion- when an individual forms a perception or attitude towards the innovation regardless if it is positive or negative.

3. Decision - takes place when an individual decides to accept or reject an innovation.

4. Implementation- an individual decides to put an innovation into practice. 
5. Confirmation- an individual seeking affirmation or reinforcement concerning the innovation.

For this capstone project, the point of knowledge for the practitioners was the day of the educational intervention. The goal of the project was for practitioners to move beyond the knowledge stage and recognize how the guidelines and resources on the website would facilitate application knowledge. From this point of application knowledge, practitioners had a greater understanding of their role, or principle knowledge, in implementing the innovation.

The second stage of persuasion could have occurred at different times for different practitioners. It may have occurred during, immediately after, or in the days that followed the multifocal training. Champions with knowledge and influence provided insight and direction for the project, and their support helped persuade other practitioners to consider the innovation. Hader et al. identified that physicians take into consideration the actions of their peers during the persuasion process (2007). The website also persuaded practitioners to adopt the practice change because it simplified the process of using the guidelines, addressed common barriers, allowed continuous access, and promoted long term sustainability.

The decision to accept or reject the innovation could have occurred during or after the educational intervention. Factors that could have affected this decision were presentation style, perceived need, patient acceptance, champion's support, and institutional support. Steps were taken to influence the decision to adopt the innovation, 
and included demonstration of the website link, opportunity for question and answer, and comparison with past multi-drug resistant programs that have provided positive outcomes. These actions correspond to what Daly et al. (2011) noted may influence practitioner decision making.

Implementation of the innovation by practitioners could have occurred at any time following the multifocal training. If a practitioner decided to implement the innovation, the implementation occurred when the practitioner treated a case of CA-MRSA SSTI and chose to follow the CDC guidelines. The ease of use of the guidelines, susceptibility data, and patient education tool should have assisted practitioners who chose to implement the innovation to continue to do so.

During the stage of confirmation, practitioners sought affirmation from others concerning the innovation. Other practitioners, patients, family members, and/or the capstone committee could have given this affirmation. Confirmation was paramount to this projects sustainability. If confirmation was consistent and positive, the probability of the innovation being successful should have increased.

Recognizing that there are variables that affect the rapidity of acceptance of an innovation, Rogers continued his theory by identifying five variables that influence acceptance (2003).

1. Relative advantage- the improvement of the innovation in comparison with the current model. 
2. Compatibility- the relationship of the innovation with the existing values, past experiences, and needs of those who potentially would adopt the innovation.

3. Complexity- the perception of the difficulty to comprehend and implement the innovation.

4. Trialability- the length of commitment needed to experiment with the innovation.

5. Observability- the extent to which the results of the innovation are visible to others.

These five variables were important for the implementation of the innovation and influenced the rate of adoption. First, practitioners needed to consider the relative advantage or the improvement of the innovation in comparison to their current practice. Second, practitioners were affected by their relationship and experiences with CA-MRSA SSTIs, evidence based practice, CDC guidelines, perceived severity of CA-MRSA, and their confidence or lack thereof in this innovation. Third, practitioners needed to assess the perceived complexity of comprehending and implementing the innovation could have also affected the rate of adoption. The website aided in decreasing barriers to use of the guidelines. Fourth, practitioners needed to consider the variable of trialability of the innovation. Trialability should have not inhibited the rate of adoption because of the relative simplicity of its implementation, low cost of implementation, and the speed at which practitioners were able to see results. Fifth, practitioners were affected by those who observed the innovation: the patient with the infection, the family of the patient, and other practitioners. 
Rogers also identified different types of adopters of innovations. He categorized these adopters into five groups: innovators, early adopters, early majority, later majority, and laggards.

1. Innovators - are first to adopt an innovation and are risk takers.

2. Early adopters - are discrete and judicious when adopting innovations.

3. Early Majority - take a significant amount of time to adopt an innovation.

4. Later Majority - are skeptical about innovations and wait for the majority to adopt it before doing so.

5. Laggards - are focused on tradition and have an aversion to change.

This multifocal intervention targeted all categories of adopters, but focused on early adopters, early majority, later majority, and laggards. It was hypothesized that innovators would have already implemented the innovation. The other categories of adopters could have potentially not had knowledge or have implemented the innovation, and therefore, were a target of this project.

Overall, the theory of Diffusion of Innovations was an excellent guide for this capstone project. The projects practice question of what is the effect of a multifocal training that educates primary care practitioners about treatment guidelines, Marion County, WV susceptibility data, I\&D technique, and a patient education tool versus common treatment practices to increase practitioner's knowledge and utilization of evidence based guidelines in the treatment of CA-MRSA SSTIs, was strengthened by the 
theory of Diffusion of Innovations as this theory guided, undergirded, and gave structure to this project.

\section{Project Description}

\section{Evidence Based Guidelines}

The CDC and the IDSA have published guidelines for the treatment of CAMRSA SSTIs. The guidelines provide direction for practitioners for identifying these infections, distinguishing severity, need for I\&D, and need for empiric antibiotic treatment. The guidelines also provide guidance for the choice of an antibiotic in the age of CA-MRSA. While the guidelines describe proper treatment, there are several barriers that hinder their use. Lack of understanding of the guidelines, lack of knowledge of regional susceptibility, and hesitance over use of I\&D have all been identified as barriers for the practitioner.

\section{Literature Review and Synthesis}

\section{Search Strategy}

Computerized literature searches of National Guideline Clearinghouse, CINAHL, PUBMED, the Cochrane Library, and the Springer, OVID, and Wiley Science full-text databases were performed using the keywords CA-MRSA, skin, soft tissue infections, antibiotics, incision and drainage, clindamycin, and trimethoprim-sulfamethoxazole (TMP-SMX or TMP-SMZ). A search strategy was developed for each database using similar keywords, and the searches were conducted using various combinations of the identified keywords. No limits were placed on publication date or type of article. The 
search was limited to pediatrics, and to the English and French languages. These searches produced 294 hits.

\section{Study Identification}

A three-step process, using the selection criteria detailed below, was used to identify articles to retain or exclude. The first step involved screening the titles and abstracts. Articles were excluded if they were not research studies, systematic reviews or clinical practice guidelines $(n=265)$. If any one of the inclusion criteria was not met, the article was not considered for use in this systematic review $(n=17)$. If the title and/or abstract did not provide sufficient information to make a determination of whether it met inclusion criteria, the full-text article was retrieved for review. The second step involved reviewing the full text of articles to verify that all inclusion criteria were met. Articles were excluded if they were not studies of treatment of CA-MRSA skin and soft tissue infections $(n=6)$, or if incision and drainage was not part of the intervention $(n=7)$. Seven articles remained, that met inclusion criteria and were retained for the review. The final step of the review process involved hand searching reference lists of all relevant articles retained to identify additional relevant articles, which were subsequently retrieved and reviewed $(n=2)$. A total of nine articles were included in this review: two clinical practice guidelines (CPG) (Stevens et al., 2005; Liu et al., 2011), two randomized control trials (RCT) (Doung, Markwell, Peter, \& Barenkamp, 2010; Schmitz et al., 2010), three cohort studies (Chuck, Frazee, Lambert, McGabe, 2010; Ruhe, Smith, Bradsher, \& Mason, 2007; Teng et al., 2009), one descriptive comparative study (Hyun, Mason, Forbes, \& Kaplan, 2009), and one expert opinion paper (Newland \& Kearns, 2008). The paper by 
Newland and Kearns was retrieved and first classified as a systematic review; following a closer reading of the review, the paper was re-assigned as an expert opinion paper. The article was retained for this review because it provided an excellent discussion of the prevention and treatment options for pediatric CA-MRSA SSTIs.

\section{Selection criteria}

Population. The focus of this review is the pediatric population, defined here as children ranging in age from 1 year to 18 years. The review excluded studies involving neonates. When few randomized controlled trials were identified that studied a pediatric population, this criteria was expanded to include adult populations and findings were interpreted with respect to transferability to the pediatric population.

Intervention. The intervention had to address treatment of CA-MRSA SSTIs with incision and drainage, either with or without antibiotics active against CA-MRSA.

Principle outcomes. The practice outcome of interest was resolution of infection. Documents were included that measured this outcome in various ways.

Study design. Articles were included if they were a research study, a systematic review or a clinical practice guideline. Research studies were included if they were randomized controlled trials, controlled trials without randomization, cohort studies, observational or comparative studies. Qualitative research and case reports were excluded. 


\section{Methods for quality assessment}

Each of the documents that met the inclusion criteria was assigned a Level of Evidence according to Larrabee's (2009) system of hierarchy. Studies, reviews and practice guidelines are ranked on a scale of $1-5$ according to strength of design, with a rank of 1 (strongest design) assigned to systematic reviews and a rank of 5 (weakest design) assigned to case reports, expert opinion papers, etc. The reviewer includes consideration of level of evidence with the additional appraisal findings to make a determination on the overall quality of each research study, review, and guideline. Table 1 presents the level of evidence and quality assessment of each article included in this systematic review.

A single reviewer critically appraised the quality of each article included in the review. The Appraisal of Guidelines Research \& Evaluation (AGREE) network guidelines (AGREE, 2006) were used to assess the quality of the CPG (Stevens et al., 2005; Liu et al., 2011). The standardized AGREE form for review of CPGs focuses on the totality of the recommendations, rather than each individual recommendation. The CPG is rated on six domains which are scope and purpose, stakeholder involvement, rigor of development, clarity and presentation, applicability, and editorial independence (AGREE, 2006). The RCTs (Duong et al., 2010; Schmitz et al., 2010), and cohort studies (Chuck et al., 2010; Ruhe et al., 2007; Teng et al., 2009) were assessed according to Scottish Intercollegiate Guidelines Network (SIGN) guidelines (SIGN, 2007). Quality assessment of the descriptive comparative study (Hyun et al., 2009) was accomplished 
with a standardized assessment form according to methodology developed by Larrabee (2009).

\section{Data Abstraction}

Data were abstracted from the six studies included in the review as part of the quality assessment process. A single reviewer entered data detailing characteristics of the included studies . More detailed and specific data about the interventions and outcomes were abstracted and entered in a separate table to facilitate summary and synthesis of findings across studies. The analysis of similarities and differences across samples, interventions, definitions and measures, and outcomes, form the basis of recommendations for practice.

\section{Study Characteristics}

Characteristics of the studies included in this review are displayed in Table 1. The settings for all six studies varied in location and specific size and type of center. Most of the studies took place in civilian medical centers (Chuck et al., 2010; Duong et al., 2010; Ruhe et al., 2007; Teng et al., 2009; Hyun et al., 2009). One study was conducted in military medical centers that sees both civilians and military personnel (Schmitz et al., 2010). Five studies were conducted in the U.S., one in multiple regions (Schmitz et al., 2010), two in the south (Hyun et al., 2009; Ruhe et al., 2007), one in the mid-central region (Duong et al., 2010) and one on the west coast (Chuck et al., 2010). Only one study was conducted outside the U.S., in Taipei, Taiwan (Teng et al., 2009). 
Data collection methods varied across studies. Retrospective record review was used in four cases (Chuck et al., 2010; Hyun et al., 2009; Ruhe et al., 2007; Teng et al., 2009). The two RCTs (Duong et al., 2010; Schmitz et al., 2010) collected data prospectively. Sample sizes ranged from 50 patients (Chuck et al., 2010) to 492 patients (Ruhe et al., 2007). Three study samples comprised adult participants (Chuck et al., 2010; Ruhe et al., 2007; Schmitz et al., 2010) with a median age of 27 years , 40 years (Chuck et al.), 47 years (Ruhe et al.), and 40 years (Schmitz et al.), The other three study samples were of pediatric participants with median age of the studies being 4 years (Duong et al.), 4.3 years (Hyun et al.), and 6.3 years (Teng et al.).

All studies differed in terms of clinical characteristics of the participants, as well as type and severity of the skin and soft tissue infection. In the studies with adult subjects, two included participants with comorbid conditions such as diabetes (Ruhe et al., 2007; Chuck et al., 2010), while the other study excluded comorbid conditions such as diabetes (Schmitz et al., 2010). Two studies, one in the pediatric population (Teng et al., 2009) and one in the adult population (Ruhe et al., 2007) characterized SSTIs as defined complicated, SSTIs by providing examples of complicated SSTIs such as a nonhealing ulcer or diabetic foot infection, postsurgical wound infection, or processes involving deep tissue structures (e.g., which include bone, fascia, or tendon sheaths). Chuck et al. also chose to define complicated SSTIs, but differently than the others. Their definition varied from the definition offered by Teng et al. and Ruhe et al. Doung et al. complicated as abscesses with surrounding cellulitis or infection in inmmunocompromised hosts or infected wounds. With this variability of definition of 
uncomplicated versus complicated SSTIs in studies, there is no clear definition to distinguish uncomplicated from complicated SSTIs. More important to this systematic review, the use of antibiotics or non-use of antibiotics was based on whether a SSTI is complicated or uncomplicated.

\section{Interventions and Outcomes}

Another area of heterogeneity was in the interventions which were the treatments of CA-MRSA SSTIs. All studies used I\&D, but the antibiotics, duration, and dosage varied. Duration of treatment with antibiotics ranged from seven (Schmitz et al., 2010) to ten days (Duong et al., 2010). Dosage of antibiotics prescribed were trimethoprimsulfamethoxazole $160 \mathrm{mg} / 800 \mathrm{mg}$ two pills twice daily (Schmitz et al., 2010) and trimethoprim-sulfamethoxazole $10-12 \mathrm{mg}$ trimethoprim $/ \mathrm{kg}$ /day divided in two doses with maximum does of 160mg trimethoprim/dose (Duong et al., 2010). The other four studies were retrospective in design and did not discuss length of treatment or dosage. Chuck et al presented multiple possibilities of antibiotics according to the algorithm, Hyun et al. examined trimethoprim-sulfamethoxazole compared to clindamycin, Ruhe et al. and Teng et al. examined active or inactivity of susceptibility of prescribed antibiotics. The dosage and length of treatment with antibiotics could affect resolution and further spread of the CA-MRSA SSTIs (Newland \& Kearns, 2008).

The outcomes of interest in these six studies were some version of treatment success or resolution of infection. As with the interventions, however, specific definitions and measurement strategies differed across all studies. Three studies identified treatment 
failure as the principal outcome (Ruhe et al., 2007; Schmitz et al., 2010; Teng et al., 2009) Ruhe et al. and Teng et al. define this as worsening signs of infection at least two days after zero time with one or more of the following: additional I\&D, subsequent hospital admission, new infection during antimicrobial therapy or persistence of MRSA from wound site, and/or need of surgical intervention. The definition of treatment failure by Schmitz et al. was similar to that of Ruhe et al. and Teng et al., but further delineated worsening of infection by defining it as increased diameter of abscess or cellulitis, fever, systemic response, and/or new lesion development within seven days of time zero. One study measured clinical resolution or failure as the primary outcome of interest (Doung et al.), and defined resolution as absence of erythema, warmth, induration, fluctuance, tenderness, and drainage at 10 day follow-up. Treatment and failure was defined as worsening of signs and symptoms before 10 day follow-up requiring drainage, change in medication, hospital admission for intravenous antibiotics, and/or new lesion development within $5 \mathrm{~cm}$ of original abscess.

\section{Findings}

Evidence from the studies appraised is homogenous for the use of I\&D in the treatment of uncomplicated CA-MRSA SSTIs, but the evidence for the use of empiric oral antibiotics with I\&D is heterogeneous. Use of I\&D alone for treatment of uncomplicated CA-MRSA SSTI is recommended in the CPG (Stevens et al., 2005; Liu et al.,2011), the expert opinion paper (Newland \& Kearns, 2008), two RCTs (Duong et al., 2010; Schmitz et al., 2010), one cohort study (Teng et al., 2009), and the descriptive comparative study (Hyun et al., 2009). Definitions of uncomplicated differed across 
studies, however. Use of I\&D and antibiotics active against CA-MRSA for what were characterized as complicated SSTI in adult patients was associated with fewer treatment failures than occurred in patients who did not receive antibiotics active against CAMRSA (Chuck et al., 2010).

One cohort study suggested that antibiotics active against CA-MRSA provided clinical improvement and noted a statistically significant difference at 48 hours between those who were started on antibiotics and those who where not (Ruhe et al., 2007).

Schmitz et al. (2010) and Doung et al. (2010) suggested that trimethoprimsulfamethoxazole may decrease the spread of CA-MRSA SSTI after the appearance of the first lesion.

\section{Discussion}

Overall, this review supports findings of use of incision and drainage alone for treatment of uncomplicated CA-MRSA SSTI in pediatric patients, when uncomplicated is defined as being an acute single infectious erythematic lesion of the skin or soft tissue that is anatomically located in an area in which I\&D can adequately be performed and does not involve adjacent deep tissue structures in an immuno-competent patient who has no signs of systemic infection. Complicated CA-MRSA SSTI should, at a minimum, be defined as an infection of the skin or soft tissue structures that does not meet the minimal requirements of an uncomplicated infection. Although this topic is of considerable interest among researchers, and numerous studies have been conducted, relatively few have used randomized controlled trials. Use of the RCT design is recommended for 
intervention research (Polit \& Beck, 2011). Also noted is the scarcity of research with pediatric participants. Although research with pediatric participants, a vulnerable population, can be challenging (Polit \& Beck), high quality evidence to guide treatment of pediatric patients is essential, particularly evidence about use of medications. Most of the existing research findings indicate that antibiotics in addition to incision and drainage are not necessary to achieve resolution of infection. However, substantial differences exist across studies in the definition of uncomplicated and complicated infections. The results of this review highlight several gaps in the research evidence about an effective treatment for uncomplicated CA-MRSA SSTI in pediatric patients.

There are several gaps that were identified in the evidence related to SSTIs and CA-MRSA. The first identified gap is the lack of clear and consistent definitions across studies for uncomplicated and complicated SSTIs, resolution of infection, and treatment failure. This limits ability to synthesize findings across studies, and to draw strong conclusions about the evidence. The second identified gap is the varying definitions of CA-MRSA. In two studies (Ruhe et al., 2007; Teng et al., 2009), CA-MRSA is defined as a specimen positive for MRSA, obtained on an outpatient visit or within 48 hours of admission, and also lacking all of the risk factors for HA-MRSA. Details related to diferentation of CA-MRSA from HA-MRSA were not provided in two studies (Hyun et al., 2009; Schmitz et al., 2010). Duong et al. defined CA-MRSA as MRSA obtained from a patient from the community susceptible to other antibiotics including vancomycin, trimethoprim-sulfamethoxazole, clindamycin, and tetracyclines. Newland and Kearns (2008) recommend molecular determination, clinical presentation, and presence of risk 
factors to identify CA-MRSA. Inconsistent identification of the infection being treated means that some may be considered to have an effect on CA-MRSA that does not exist, because the SSTI was not actually caused by CA-MRSA. The third identified gap in the evidence is the lack of research, beyond the RCTs, with findings suggesting a benefit from use of trimethoprim-sulfamethoxazole for prevention of secondary lesions. These studies suggest an avenue for research that has not yet been addressed. Long-term followup for intervention studies for CA-MRSA SSTIs will help researchers and practitioners understand whether the sentinel infection recurs, if repeated infections are more likely among patients who have a history of infection, or if a particular treatment is associated with more or less likelihood of recurrent infection.

Weaknesses in the methodology of the reviewed studies were identified. Compliance with treatment was defined in one RCT (Doung et al. 2010) as taking $50 \%$ or more of prescribed medication. The researchers verified the amount of medication taken by quantifying study medication on the return visit or parental report over the phone (Doung et al., 2010). Although there is no specific percentage that signifies adequate adherence to medications, $80 \%$ is commonly seen in the literature as acceptable (Andrade, S.E., Kahler, K.H., Frech, F., Chan, A., 2006). The level of 50\% is far below this average and could be a confounder in this study.

Duration of follow up after treatment was finished was limited to 30 days in two studies (Hyun et al., 2009; Schmitz et al., 2010), 90 days in one study (Doung et al., 2010), and was unspecified in two studies (Ruhe et al.,2007; Teng et al., 2009). One RCT (Schmitz et al., 2010) noted the poor follow-up (69\%) at 30 days following infection. 
Both RCTs (Doung et al., 2010; Schmitz et al., 2010) were convenience samples among emergency department patients and may affect generalizabilty. Convenience sampling imparts the risk of selection bias.

One RCT noted there was no standardized I\&D procedure and practitioners did not follow a standardized protocol for measurement and assessment of the SSTIs (Schmitz et al., 2010), one RCT had a standardized protocol (Duong et al., 2010), one study described the I\&D as an operating room procedure using general anesthesia (Hyun et al., 2009), and the other three studies did not describe I\&D procedures or its standardization (Chuck et al., 2010; Ruhe et al., 2007; Teng et al., 2009). This lack of information and standardization makes it impossible to replicate the studies.

Two cohort studies had small group sizes for their cohorts and did not provide confidence intervals (CI) (Chuck et al., 2010; Teng et al., 2009). Two studies did not provide details of a power analysis which affects the ability to differentiate if I\&D, antibiotics, or both were responsible for resolution (Chuck et al., 2010; Hyun et al., 2009). Another study included multiple infections from the same persons in the study and failed to provide a clearly defined explanation of treatment failure (Ruhe et al., 2007). There were several threats to internal validity in the descriptive comparative study. As a significant variance from the other studies the majority of the participants was admitted to the hospital and received parenteral clindamycin before discharge (Hyun et al., 2009). The administration of clindamycin could have acted as a confounder in this study. This study did not include CIs that would allow for assessment of the power of the study. 
Despite these methodological limitations, some key findings of the review merit discussion. Evidence from the studies appraised is homogenous for the use of I\&D in the treatment of uncomplicated CA-MRSA SSTIs. The CPG (Stevens et al., 2005), two RCTs (Duong et al., 2010; Schmitz et al., 2010), one cohort study (Teng et al., 2009), the comparative/descriptive study (Hyun et al., 2009), and the expert opinion paper (Newland et al., 2008) supported the use of I\&D alone in treatment of uncomplicated CA-MRSA SSTIs.

The evidence for the use of empiric oral antibiotics with I\&D is heterogeneous. One cohort study supported the use of an algorithm with antibiotics active against CAMRSA in the treatment of uncomplicated SSTIs, but advised the practitioner to strongly consider not using antibiotic therapy (Chuck et al., 2010). One cohort study suggested that antibiotics active against CA-MRSA provided clinical improvement and noted a statistically significant difference at 48 hours between those who were started on antibiotics and those who where not (Ruhe et al., 2007). Schmitz et al. (2010) and Doung et al. (2010) suggested that trimethoprim-sulfamethoxazole may decrease the spread of CA-MRSA SSTIs after the appearance of the first lesion.

\section{Dissemination Methods}

Two studies were identified that addressed the education of practitioners concerning evidence based treatment of CA-MRSA SSTIs. The first is an Iowa Research Network Intervention (IRENE) study that had as its objective to identify best methods and procedures for primary care practitioners to treat SSTIs (Daly et al., 2011). The study 
was a preintervention/postintervention design and had as its main outcome measure the use of antibiotics that would cover MRSA on intial visit and at any time. Educational meetings were conducted that discussed CA-MRSA SSTIs treatment including the CDC guidelines and office policies on treatment. The researchers concluded that the CDC guidelines are applicable and functional in the primary care office setting and that after SSTI management discussions practitioners increased use of antibiotics with MRSA coverage both initially and overall (Daly et al.,2011). The researchers also concluded that including practitioners in discussions concerning guidelines was more effective than just providing guidelines in changing physician practice.

The second study conducted an electronic chart audit to investigate the prevalence of CA-MRSA and those cases that were treated according to the CDC guidelines on outpatient management of CA-MRSA SSTIs (Parnes et al.,2011). A historical cohort was compared with an intervention cohort that received education and a ready made kit for education and treatment of CA-MRSA SSTIs. Researchers concluded that the intervention group increased use of antibiotics that covered CA-MRSA, but did not increase use of I\&D or culture (Parnes et al.,2011). The researchers questioned the results of the lack of increase in I\&D procedure and hypothesized that possibly the I\&D procedure was being conducted and not coded, and recommended relying more on a physician or point of care data collection method rather than chart audits or electronic data capture as the "gold standard." 


\section{Implications for practice}

Practitioners and researchers have documented an increase in pediatric CAMRSA SSTIs. Therefore, an efficacious and judicious treatment plan is needed to treat pediatric CA-MRSA SSTIs and slow the further development of antibiotic resistance. Based on this review, treatment of uncomplicated pediatric CA-MRSA SSTIs with I\&D is recommended. This review does not identify conclusively that the use of antibiotics decreases initial uncomplicated CA-MRSA SSTI resolution, but does support the possibility that use of antibiotics may decrease secondary lesions. This possibility is suggested by evidence from a single study, however, and should be considered tentative. Evidence suggests that choice and timing of initial antibiotic and I\&D for treatment of SSTIs affects speed of resolution and subsequent lesion outcome. When choosing to treat a pediatric patient for an uncomplicated CA-MRSA SSTIs, the practitioner needs to consider patient history, location of the infection, size of lesion, community prevalence of CA-MRSA and its susceptibility, history of antibiotic use, family or close contact history of CA-MRSA, immunocompetence, and physical signs of the patient. The recommendations from this review are dependent on both the definition of uncomplicated and complicated SSTIs and the definition of CA-MRSA. Treatment recommendations depend on accurate identification of CA-MRSA and definition of uncomplicated versus complicated SSTIs. It is paramount that practitioners and researchers be aware of the variations in the definitions of uncomplicated and complicated SSTIs and CA-MRSA that have been used in studies. Practitioners and researchers should compare their definition with those used in the studies to assure their definition matches those used in the studies. 
Future research should focus on RCTs in the pediatric population, include a standardized, reliable, method for identification of CA-MRSA, and provide clear and explicit definitions of uncomplicated versus complicated SSTIs. Consideration of how short and long-term resolution and treatment failure should be defined and measured, is important to support confidence in treatment effect. In the area of resolution of infection, future studies could also focus on the both the short and long-term benefits of using antibiotics with the sentinel SSTI. If I\&D is adequate to treat the initial SSTI and provide short-term resolution, but subsequent lesions occur days and months after, then it may be necessary to consider long-term resolution and possibly antibiotic use when initially treating the sentinel lesion.

There are multiple recommendations for practice as a result of this systematic review. First, practitioners must assess and reflect on their current practice of identifying, classifying, and treating SSTIs. In this reflection, it is important for practitioners to consider their I\&D technique and their comfort level with I\&D. Second, it is recommended that practitioners evaluate how long they follow-up patients and their family members treated for SSTIs and assess if this follow up is adequate to assess for both short and long-term resolution. In practices with multiple partners, it is recommended that a standardized classification and treatment plan be agreed upon and followed. It is recommended that practitioners agree upon what classification of SSTIs warrants the use of antibiotics. This will enable continuity of care for SSTIs within the practice and allow for follow up data on efficacy to be collected. Third, a recommendation would be a continuing education initiative targeting both clinicians and 
families. These initiatives could address the adherence to accepted treatment plans among practitioners and present guidelines an interactive session, since these types of session have been shown to increase practitioner adherence over purely didactic sessions. Educational activities for families could equip them in the prevention and early recognition of CA-MRSA SSTIs.

\section{Project}

\section{Background}

Practitioners and researchers have documented an increase in communityacquired methicillin resistant staphylococcus aureus (CA-MRSA) skin and soft tissue infections (SSTIs). This increase causes stress and concern for the individuals infected and the families of those infected. Practitioners are confronted with evolving bacterial resistance, lack of understanding of the $\mathrm{CDC}$ guidelines, lack of patient educational tools, and insufficient skill in performing I\&D. Therefore, a multifocal training that educated primary care practitioners about the CDC treatment guidelines for SSTIs, Marion County, WV susceptibility data, I\&D technique, and a patient education tool was introduced to practitioners in Marion County, WV.

\section{Theoretical Framework}

Everett Rogers's theory of Diffusion of Innovations was used to guide this project. Rogers developed the theory of Diffusion of Innovations to explain and describe social change. Initially, Rogers studied the diffusion of agricultural innovations and specifically why some farmers adopted new technologies and advancements and others 
did not. Rogers continued drawing conclusions and identified regularities concerning diffusion that are found across cultures, innovations, and the people who adopt the innovations.

For the purpose of this project, the theory's five stages that occur in the adoption of an innovation were used to frame the steps to be taken to implement change in the treatment of CA-MRSA SSTIs. Evidence from the systematic review revealed that practitioners were not using an evidence-based approach when treating these infections, and change in treatment practice was imperative. Therefore, the investigator focused on moving practitioners from knowledge to implementation via the steps of knowledge, persuasion, decision, implementation, and confirmation.

A parallel application of the theory of Diffusion of Innovations in this project was the targeting of the different adopters of change. For this project, early adopters, early majority, late majority, and laggards were targeted for moving from knowledge to implementation of evidence based treatment of CA-MRSA SSTIs. Rogers identified these groups as those who have some resistance to change.

\section{Goal}

The purpose of this capstone project was to assess the effectiveness of a multifocal training to improve the treatment of CA-MRSA SSTIs in Marion County, WV. The theory of Diffusion of Innovations provided structure and guidance for the project. Practitioners were provided with a multifocal training and corresponding website (innovation). The training and the website were used to encourage (persuasion) them to 
begin to use evidence based guidelines and provide them with the resources to do so. After the completion of the multifocal trainings, practitioners made the decision to follow the evidence based guidelines and use the website resource. Implementation of the innovation occurred when the practitioners used the guidelines and resources. Confirmation occurred by monitoring hits on the website and practitioner feedback.

\section{Setting for Project}

Marion County is located in north central WV. The county seat is Fairmont, which is located 20 miles from Morgantown, WV. The total population of Marion County is 56,706 (U.S Census, 2009). The median age is 39.9 years of age. While there were no specific data available on the total number of practitioners in the county, it was known that there are more than 120 practitioners with practice privileges at Fairmont General Hospital (FGH).

The site for the capstone project was FGH, which is located in Marion County. The hospital's mission statement is "making a difference in people's lives." FGH vision statement is "THE respected name in healthcare." FGH has a statement of values that emphasizes their commitment to service, excellence, integrity, respect, and compassion. By promoting the use of evidence-based guidelines for the treatment of CA-MRSA SSTIs, this project is congruent with the mission, vision, and values of FGH and reinforces its commitment to these. 


\section{Project Objectives}

The specific outcomes that were measured as part of this capstone project were: practitioner knowledge and subsequent utilization of the CDC guidelines on treatment of CA-MRSA SSTIs, antibiogram, I\&D, and patient/family education following a multifocal training as evidenced by improvement of scores from pretest to posttest, no loss of knowledge at three month follow up, and self-report of utilization of the guidelines and website in treatment of CA-MRSA SSTIs. Following are the specific objectives of the project:

1. By completion of the multifocal training, practitioners will improve their knowledge of CA-MRSA SSTIs evidenced by improved scores on the pretest to posttest.

Specifically practitioners will be able to:

a. List the basic treatment pathway outlined in the CDC guidelines (Appendix D) for the treatment of CA-MRSA SSTIs.

b. List antibiotics (Appendix E) that can be used to effectively treat CAMRSA SSTI in Marion County, WV.

c. Identify proper technique for I\&D.

d. List one tool (Appendix C) for educating patients and families about CAMRSA. 
e. Identify the website (Appendix B) that provides the components of the guidelines, antibiogram, I\&D video, and patient education tool.

2. Practitioners self-report using the CDC guidelines, antibiogram, $I \& D$, and patient/family education tool in treatment of patients with CA-MRSA SSTIs on the three month follow up evaluation.

3. Knowledge gained from the multifocal training will not be decreased at threemonth follow-up as evidenced by maintenance of first posttest scores.

4. The website will have fifty hits on the site by the three-month follow-up date.

\section{Design}

This capstone project was designed to promote a practice change in the treatment of CA-MRSA SSTIs by utilizing a multifocal training to educate primary care practitioners about the CDC's evidence-based guidelines and present tools to address the barriers that prohibit practitioners from using the guideline.

Training for the practitioners included:

1. Administration of an author developed pretest (Appendix G) to assess practitioners' knowledge of the CDC guidelines, antibiogram, I\&D and patient education tools were administered before the presentation.

2. Presentation of current antibiotic resistance, CDC guidelines, regional antibiogram, techniques for I\&D, and a patient educational tool (Appendix C). 
These presentations occurred in a lunch or dinner setting with the voluntary participation.

3. Use of the website (Appendix B) that provided practitioners with access to the guidelines, antibiogram, I\&D video, and patient education tool was emphasized.

4. Dialogued with practitioners to address their concerns and barriers to using the CDC guidelines.

\section{Resources}

Resources for this project were identified during the preparation stage. Barriers and facilitators were considered so that judicious planning would make wise use of available financial and personnel resources. The investigator identified the following resources as paramount for this projects success: expert committee and contributors, permission for use of materials, participants, and a budget plan.

The expert capstone committee and contributors provided the foundation for this project. Dr. Alvita Nathaniel served as the chair and provided the structure and expertise in conducting a capstone project. Janet Crigler, Director of Infection Control at FGH, provided invaluable support, insight, and community influence, which greatly contributed to this project meeting its outcomes. Crigler was initially contacted early on in the preparation stage of the project. She provided contact with contributor, Dr. David Meyer. Meyer was instrumental in giving insight into interpretation and use of FGH's antibiogram. Meyer suggested contacting Dr. Uday Kumar, infectious disease specialist at FGH, for his insight and thoughts. Kumar recommended the use of the Michigan 
Antibiotic Resistance Reduction Coalition (MARR) pamphlet for an educational tool for the project. Dr Michael Levitas has provided instruction and mentorship throughout the investigator's career, and continued to do so throughout this project. He served on the capstone committee and provided expert insight into the treatment of CA-MRSA SSTIs specifically for the pediatric population, which is most affected by CA-MRSA SSTIs.

Permission for use of materials was a necessary resource for this project and obtaining permission required a significant amount of time. The CDC was contacted first about posting the guidelines on the website. Permission was given, as the guidelines are public access. Both Janet Crigler and Dr Meyer provided assistance in securing permission from FGH to use the hospital's antibiogram. Dr. Kumar suggested contacting MARR to obtain their permission to use their educational handout. Jane L.Finn granted permission from MARR. The New England Journal of Medicine was contacted and permission was granted by Jennifer Moran to use the I\&D video that was produced for the journal.

A budget plan assisted in focusing financial resources in strategic areas. Appalachian Spring Dermatology provided the financial resources necessary for the webpage, multifocal trainings, office supplies, and evaluations. FGH contributed the expertise of Janet Crigler and David Meyer and its antibiogram. The space needed for the teachings was provided without charge by each participating clinic. The expertise and time of the members of the capstone committee, Alvita Nathaniel, Janet Crigler, and Michael Levitas, and contributors, Uday Kumar, David Meyer, and Beth Rosenberger, were paramount for consensus of this project, but it was difficult to assign a financial 
amount for their time and expertise. Overall, the cost of the project was minimal in comparison with its impact. Practitioners' use of evidence-based guidelines, exercise of antibiotic stewardship, and the optimization of use and limitation of misuse of antibiotics are invaluable.

\section{Timeline of Project Phases}

A timeline was first developed in the planning stages of the project. Activities were divided up according to whether they fell in one of three sections: preparation, implementation, or evaluation. Although, the dates that were originally assigned to the timeline changed, the actions remained the same.

\section{Preparation}

The activities that occurred during this stage included those that needed to be completed before the stage of implementation.

- The investigator obtained permissions from the CDC, New England Journal of Medicine, FGH, and MARR for use of their perspective materials for this project.

- The investigator met with the WVDHHR concerning the project and possibility for statewide adoption.

- A website (http://wvcamrsa.com) was developed by the investigator as an ongoing resource for which practitioners could refer. 
- The investigator scheduled meetings with clinics within Marion County, WV for the multifocal trainings.

\section{Implementation}

This stage consisted of the multifocal trainings and gathering of data that would be used in the final stage of evaluation.

- From July 22, 2012 to August 10, 2012, the investigator conducted multifocal trainings at six different clinics in Marion County. These multifocal trainings consisted of consent for participation, pretest, instructional and interactive training, posttest, and explanation and distribution of follow-up evaluation.

- The website (http://wvcamrsa.com) was launched on July 22, 2012, which was the day of the first multifocal training.

\section{Evaluation}

This stage consisted of evaluating the gathered data from the pretest, posttest, and threemonth follow-up evaluation.

- The investigator obtained 22 pretests and 22 posttests from participants at six clinics in Marion County, WV.

- The investigator conducted statistical tests to analyze the data and to ascertain the significance and effectiveness of the training. 
- The investigator examined the retention of knowledge and the movement from knowledge to implementation from the three-month follow-up evaluation.

- The investigator monitored unique hits on the website throughout the study period.

The project was conducted at six clinics in Marion County, WV with 22 participants. The data collected from the pretest, posttest, and three- month follow-up were evaluated. The results from the project will be submitted to the WVDHHR for the purpose of initiating the project on a statewide level.

\section{Evaluation}

Following the data collection, the investigator evaluated the project objectives. The first objective was: By completion of the multifocal training, practitioners will improve their knowledge of CA-MRSA SSTIS evidenced by improved scores on the pretest to posttest. This objective was met. There were six multifocal trainings conducted that consisted of sixteen doctors, three nurse practitioners, and three physician assistants. Following the multifocal training, all participants' knowledge improved from pretest to posttest.

The second objective was: Practitioners self-report using the CDC guidelines, antibiogram, I\&D, and patient/family education tool in treatment of patients with $C A$ MRSA SSTIs on the three- month follow- up evaluation. This objective was met. Six practitioners reported using the $\mathrm{CDC}$ guidelines, antibiogram, I\&D, and patient education tool in treatment of CA-MRSA SSTIs. Two participants reported referring other 
practitioners, who did not participate in this study, to the website and one participant reported referring a drug sales representative to "spread the word."

The third objective was: Knowledge gained from the multifocal training will not be decreased at three- month follow-up as evidenced by maintenance of first posttest scores. This objective was met. However, the number of submitted follow-up evaluations was low. There were six follow- up evaluations received. However, only two of these six were totally completed evaluations. These two evaluations received scores equaling those on their posttest, demonstrating retention of knowledge and no loss of knowledge at the three -month follow-up evaluation.

The fourth objective was: The website will have fifty hits on the site by the threemonth follow-up date. This objective was met. On July 26, 2012, the fourth day following the website launch, the fiftieth hit on the website was recorded. The website was readily accessed throughout the investigation period.

\section{Project Results}

The purpose of this project was to train practitioners in Marion County, WV on the CDC guidelines for treatment of CA-MRSA SSTIs and to provide resources to address some of the most common barriers that inhibit practitioners from using the guidelines. Research supports the use of these guidelines and has also supported that there are common barriers to not using the guidelines. Evidence-based treatment of SSTIs is imperative to decreasing the rapidity of antibiotic resistance and practicing antibiotic stewardship. 
After discussing this project with WVDHHR, it was decided that this project should not be focused statewide, but rather should be "piloted" in one county to examine whether there was a need. Marion County was chosen as the county to pilot the program. There were five areas of data collection that were used to provide framework for evaluating the effectiveness of the multifocal training.

The first area of data collection in the evaluation process was demographics of the participants. The participants included sixteen doctors, three nurse practitioners, and three physician assistants. The range of years in practice ranged from several months to more than twenty-five years of practice. The gender make up of the participants was thirteen males and nine females.

The second area of data collection in the evaluation process was the results of the pretest and posttest that assessed the knowledge acquisition and effectiveness of the educational program. The data was examined to see if there was any significance between the pretest and posttest and to examine whether or not the multifocal training was effective. There were nine questions on the identical pretest and posttest. A paired ttest was conducted comparing the results. The null hypothesis that there was no significant difference or lack of knowledge acquisition in comparing pretest to posttest scores was rejected. The one tailed t-test revealed that the posttest scores were greater $(\mathrm{m}=8.32, \mathrm{~s}=.716)$ compared to pretest scores $(\mathrm{m}=4.45, \mathrm{~s}=2.132), \mathrm{t}(21)=-7.897, \mathrm{p}<.05$. Thus, the first objective was met. 
The third area of data collection was the results of the three-month follow-up evaluations. The data was examined to assess for knowledge retention at the three-month follow-up period. Of the six follow-up evaluations received, only two were totally completed. These two participants scored the maximum points possible on the follow-up evaluation, which corresponded, to their respective posttest. With the small number of returned follow-up evaluations, no statistical tests were used to evaluate this data. Thus, it is not known if the second and third objectives were met.

The fourth area of data evaluation was the use of the website (http://wvcamrsa.com). Both Google Analytics and Weebly Statistics were used to monitor use of the site. As of October 2, 2012, the total number of unique hits on the website was 565. During the investigation period, the mean number of unique hits on the website per day was eight. The home page received the most amount of hits followed by the antibiogram, CDC guidelines, I\&D video, and the patient education resource. Direct hits on the website accounted for $94 \%$ of all the hits on the website. The most common referring search engine was Google accounting for $4 \%$ of the hits on the website, and the remaining $2 \%$ was made up from several other search engines. Thus, the fourth objective was met.

The findings from this project demonstrated statistical significance. Practitioners did not demonstrate sufficient knowledge of CDC treatment guidelines, regional antibiograms, I\&D technique, or patient educational materials before the multifocal training. This project supported the research finding that practitioners are confronted by several barriers in treating patients with SSTIs in the era of CA-MRSA, but when provided with tools to address these barriers are ready to treat CA-MRSA SSTIs 
according to evidence-based guidelines. The number of hits on the website supported use of such a tool for future projects. The data from this project support the implementation of this project on a statewide level.

\section{Discussion}

This research project provided several compelling findings. These findings were both general and specific in nature. The findings could be used to guide future research projects and more specifically assist practitioners in treatment of CA-MRSA SSTIs.

Concerning the multifocal trainings, the investigator had concern about the reception and acceptance of a project by other disciplines. The investigator had hesitation that other practitioners with different hierarchical positions in the medical system would not be open or would be suspect of a project conducted by a nurse practitioner. The findings from this project did not support this concern. Practitioners, across the hierarchy, were open, appreciative, and receptive of this project. At no time in any of the six locations were the investigators' concerns realized. It must be noted that community healthcare leaders/supporters, Janet Crigler and Beth Rosenberger, undoubtedly provided both access and perceived value to the project. Overall, this project supported the role of nurse practitioners as both initiators and promoters of evidenced-based care.

Another interesting finding from the project was the questions most commonly missed on the pretest and posttest. The two most commonly missed questions on the pretest were "When treating a SSTI, you would provide empiric coverage for CA-MRSA if you know the prevalence in Marion County is greater than" and "In your experience 
what is current prevalence of CA-MRSA in Marion County." These two questions were answered incorrectly by 13 of the 22 participants on the pretest. The incorrect responses signaled lack of knowledge of regional antibiograms and CA-MRSA prevalence within the community. The questions "When you are considering a diagnosis of an uncomplicated versus complicated SSTI, which one of the following criteria is least important" and "When you consider the susceptibility data for Marion County, which of the following would be the best choice for outpatient treatment of a complicated SSTI" were incorrectly answered by 10 of the 22 participants. These questions signaled lack of knowledge of treatment guidelines. The most commonly missed posttest question was "When you are considering a diagnosis of an uncomplicated versus complicated SSTI, which one of the following criteria is least important?" of which five participants had the incorrect response. The data supported that the multifocal training was successful in increasing practitioner knowledge in these critical areas.

Another interesting assessment was the lack of time practitioners have to participate in activities such as the one that was presented in this project. When scheduling the trainings, it was evident that practitioners were bombarded from many different directions with each direction/person vying for the practitioner's limited time and attention. It was noted that the key to successfully scheduling the meetings was the nurse or administrative assistant who often had significant input and control of the practitioner's schedule. This assessment of lack of time may have also contributed to the relatively low number of completed follow-up evaluations. Six evaluations were received, but only two were completed entirely. Practitioners might have not considered 
the follow -up evaluation a wise investment of their limited time or only chose to fill out the sections they deemed important. Overall, the benefit of this project was that it was relatively short in nature and provided practitioners with a resource website that could be used at a later time.

\section{Project Outcomes}

The project's outcomes supported future activities and trainings in the area of CAMRSA SSTIs on a local and state level. Outcomes supported the idea that practitioners are interested in projects that not only provide knowledge, but address barriers that prevent or could prevent practitioners from implementing guidelines. Technological advances, such as websites, are valuable tools for practitioners to put knowledge into practice. Lastly, the findings from this project support the need for this project to expand statewide so that all practitioners in WV can have access to guidelines, regional antibiograms, I\&D technique, and patient educational materials when they are treating CA-MRSA SSTIs.

\section{Intervening Factors}

Although attempts were made to decrease confounders in this project, there were several that were identified. The first factor that may have contributed to the results of the project was the lower than anticipated number of participants. The investigator's goal was to train 50 practitioners during the project. The project was conducted during the summer months. The investigator hypothesizes that the number of participants was lower than expected, because this is a common time for vacations and planned time off. For 
future projects that desire higher participation, it would be of importance to choose a time of year that is not as common for vacations and time off.

The second factor that may have contributed to the results was the practitioners' past exposure to information on CA-MRSA SSTIs. The results from the pretest supported that practitioners had not been successful in retaining past knowledge on CA-MRSA SSTIs. The three-month follow-up evaluation was of importance to assess whether practitioners maintained knowledge and implemented that knowledge following the multifocal training. The low number of completed returned follow-up evaluations prevented statistical evaluation. All six participants who returned their follow-up evaluation reported use of the website resource and implementation of evidence-based practice in the treatment of CA-MRSA SSTIs.

The last factor that may have affected results of this project was that the main resource for the project was computer/internet based. When asked about copies of the guidelines, antibiogram, patient education tools, and I\&D video, the investigator did not give practitioners samples, but referred them to the website for downloading and printing of the resources. This methodology served two purposes for the project in that it limited the cost of printed materials and encouraged the participants to visit the website. Based on the number of hits on the website during the project, the site was readily used. However, practitioners who were neither comfortable nor interested in using this type of technology could have been limited in their use of the resource tool and may have benefited from handouts. This was an identified barrier that could have affected the results. 


\section{Theoretical Framework}

Everett Rogers's theory of Diffusion of Innovations was used to guide this project. Rogers developed the theory of Diffusion of Innovations to explain and describe change. The theory's five stages that occur in the adoption of an innovation were used to frame the steps to be taken to implement change in the treatment of CA-MRSA SSTIs. This theory and the framework it provided were a perfect fit for this project. The theory provided framework, but was not rigid. Practitioners were moved from lack of knowledge, to knowledge, and then to implementation in the treatment of CA-MRSA SSTIs. An important factor in promoting change for this project and moving practitioners from to knowledge to implementation was the availability of the website tool.

Practitioners reported that in the past they had knowledge of the guidelines, but failed to implement them because of lack of tools to address the barriers. Practitioners reported that the website provided them with the necessary resources to overcome barriers that would have otherwise prevented the move to implementation. For future projects promoting change, researchers should identify common barriers and then provide a userfriendly website resource.

\section{Implications}

\section{Further Practice Implications}

Findings of the systematic review that was conducted for this project, highlighted issues that health care providers should consider with respect to their own practice. Consistency in identification, classification and treatment of pediatric CA-MRSA SSTIs 
is essential. In practices with multiple partners, a standardized classification and treatment plan is recommended. Practitioners should agree on the SSTIs classification that warrants use of antibiotics, to enable continuity of care and allow for follow up data on efficacy to be collected. When I\&D is provided as treatment, consistency in performance across clinicians is also important. Duration of follow up for pediatric patients treated for CA-MRSA SSTIs needs to be adequate to assess for both short- and long-term resolution of infection. And, finally, education to equip families for prevention and early recognition is a key element in the comprehensive management of CA-MRSA SSTIs

This project was the first of its kind in Marion County, WV and proved to have statistically significant results. This project was supported by the previously mentioned systematic review. It was in congruence with FGH's mission of "making a difference in people's lives." Practitioners were moved from knowledge to implementation of evidence-based guidelines when treating CA-MRSA SSTIs. In the planning stages for the project, dialogue was initiated with the WVDHHR. During this dialogue with WVDHHR, it was suggested that this project be "piloted" in one county. If statistically significant results were achieved in one county, it would then be considered for statewide adoption. The statistically significant results of this project will be sent to WVDHHR for consideration for statewide adoption and at minimum linking the website for this project to the WVDDHR website as a resource for practitioners across WV. 


\section{Implications for DNP Practice}

CA-MRSA SSTIs are proving to be prominent in the community, contagious, difficult to treat and eradicate, and at times, lethal. Dermatology specialists including medical doctors, APNs, and nurses are actively engaged in the battle to treat the current infections without creating further bacterial resistance. Zaccagnini and White (2011) differentiated medicine from nursing, when they wrote that medicine focuses on the diagnosis and treatment of disease, but nursing focuses on the human response to illness and its treatment. Parse (1992) also contributed when she explained, "nursing science has a unique body of knowledge that contains theories and evidence intuited, observed, and tested by nurses involved in the process of human health." Therefore, the advance practice nurse (APN) can address CA-MRSA's treatment and prevention from a caring perspective that utilizes unique nursing skills, theories, and body of knowledge in an evidenced-based manner.

With the understanding of the value of the APN practicing at its highest level within the healthcare system, The American College of Nursing (2006) published The Essentials of Doctoral Education for Advanced Nursing Practice. This document serves as a guide for developing Doctor's of Nursing Practice (DNP) programs so that the DNP trained APN will embody the highest level of leadership and expertise in specific areas of clinical practice. This document also helped differentiate between the $\mathrm{PhD}$ and the DNP. The PhD in nursing was seen as developing new knowledge and the DNP as using knowledge that already exists and putting it into practice. As the nursing profession 
continues to grow in its development and use of theory in education, practice, and research, both the $\mathrm{PhD}$ and $\mathrm{DNP}$ will prove invaluable.

This capstone project demonstrated several characteristics outlined in the American College of Nursing's (2006) The Essentials of Doctoral Education for Advanced Nursing Practice that demonstrate the role of the DNP. The first characteristic that was demonstrated was the use of scientific underpinnings for practice. This project was based on systematic review CA-MRSA SSTIs that searched the literature for the highest level of evidence available. The results of this systematic review provided the basis and support from the literature. This project also used a theory from the social sciences as its framework. By doing so, it demonstrated the integration of knowledge from nursing with other disciplines to further demonstrate nursing practice on its highest level.

The second DNP characteristic that was demonstrated was ability to provide organizational and systems leadership for quality improvement. The investigator realized that for this project to have long-term impact and to bring about real practice change, that it must be integrated or coordinated with existing agencies or health providers. This project involved consulting and working with the WVDHHR, FGH, and several practices within Marion County. The investigator analyzed the systems that were in place and the services that were being provided. Through this analysis, the investigator realized that many of the components for providing evidence-based care in the treatment of CAMRSA SSTIs existed, but were not cohesive. The investigator also identified that providing a resource to practitioners would also decrease healthcare cost and unnecessary 
side effects from unwarranted antibiotic use. This project provided cohesion by bringing the necessary components and resources together and presented it to practitioners so that they could provide high quality cost effective care to their patients.

The third characteristic that was demonstrated during this project that reflected an APN with DNP training was the use of technology and informational systems to improve patient care. In the nursing profession, technology has been resisted at times because of concerns about how it would affect the quintessence of nursing, patient care. However, the DNP nurse is able to leverage technology to provide more efficient and quality care, rather than diminish or detract from it. For this project, a website was developed as a learning and resource tool for practitioners. The investigator had no experience in website development, but was convinced it was paramount to the project's success. With input from professionals with website development skills and insight from experts in healthcare, a quality website was developed without expending large amount of resources. The website provided practitioners with the ability to access the resource from any location where they had internet connection. This technology reduced the cost of printing and distributing handouts, but also provided the resource in a user-friendly cohesive manner.

\section{Implications for Future Research}

This capstone project supported that practitioners can be moved through the change process if common barriers that would prevent implementation are addressed. Practitioners must not only be equipped with knowledge, but the tools and resources to 
address barriers. There were several areas that were identified that warrant more research concerning the treatment of CA-MRSA SSTIs.

The systematic review identified important areas that need further research. Future research should focus on RCTs, specifically in the pediatric population, include a standardized, reliable, method for identification of CA-MRSA, and provide clear and explicit definitions of uncomplicated versus complicated SSTIs. Consideration of how short and long-term resolution and treatment failure should be defined and measured, is important to support confidence in treatment effect. In the area of resolution of infection, future studies could also focus on the both the short and long-term benefits of using antibiotics with the sentinel SSTI. If I\&D is adequate to treat the initial SSTI and provide short-term resolution, but subsequent lesions occur days and months after, then it may be necessary to consider long-term resolution and possibly antibiotic use when initially treating the sentinel lesion. Each of these topics is paramount to provide better care for patients and to provide a more specific standard of treatment.

Another area that was warrants further research is the whether information technology is acceptable for practitioners across the generational and professional spectrum. Studies could focus on whether or not there is generational differences in adoption of technology and if so what actions could be taken to reduce stress in the adoption process. Research could also focus on evaluating if specific disciplines are more apt to use information technology and how the DNP compares to other professions. 
This research project did not identify that other disciplines were resistant to an APN introducing change, but this area also warrants further exploration and research. Studies could focus on whether or not change is more readily accepted if the change is introduced inter or intra professionally. Researchers could also focus on whether or not practitioners are willing to move through the change process if a doctoral trained practitioner versus non-doctoral trained practitioner presents the innovation. Each of these proposed areas concerning the change process could identify areas that would decrease the frustration sometimes felt by the change agent and the participants.

\section{Implications for Education}

The concept of evidence-based practice has been met with mixed responses in the practitioner community. At times, nursing has resisted evidence-based practice as something that medicine has developed and is not applicable to the art of nursing. Individuals in the medical community have also resisted evidence-based practice as something that turns medicine into a "cookie cutter" methodology. Therefore, educating practitioners on evidence-based guidelines can be difficult due to these barriers and resistance to change. During the systematic review, the researcher identified two very important strategies that could assist when educating practitioners. If these strategies are adopted, it is possible that education can more rapidly move from knowledge to implementation.

The first strategy was that including practitioners in discussions concerning guidelines was more effective than just providing guidelines for changing practitioner 
practice. Coles (2002) also supported this by contributing that professional judgement is often gained through interaction and conversations with respected colleagues, rather than didactic sessions. Practitioners have traditionally functioned under cognitive dissonace, being rewarded for what they know, but not being rewarded for asking questions and seeking out answers. This system does not allow for the interaction and conversations that this project has identified as beneficial. During the education of practitioners, it would be beneficial to introduce a more balanced approach and one that relies less on cognitive dissonance and more on interaction and inquiry.

The second strategy for educating practitioners in evidence-based practice is equipping them with resources to address common barriers. Although this appears simplistic, it is an area that can be neglected. During this project, the investigator ascertained that practitioners had heard of the guidelines that were available for treatment of CA-MRSA SSTIs, but resisted change because they were not provided with resources to address the barriers. If practitioners are to adopt evidence-based practice, the training must move beyond information only, but must include educating practitioners on available resources.

\section{Summary}

Despite current recommendations for incision and drainage (I\&D) to be the primary treatment for uncomplicated CA-MRSA SSTIs (Gorwitz, 2008; Liu et al., 2011), substantial practice variation in use of I\&D and antibiotic prescription persist (Baumann, 2011; Hersh et al., 2009). Increasing consistency and use of evidence-based care is 
important to both prevent inadequate treatment and improve patient outcomes. Appropriate antibiotic prescribing practices are particularly important to help reduce the spread of antibiotic resistance (Gorwitz, 2008). Evidence-based practice can potentially both improve patient outcomes and reduce the risk of adverse outcomes.

The purpose of this project was to train practitioners in Marion County, WV on the CDC guidelines for treatment of CA-MRSA SSTIs and to provide resources to address some of the most common barriers that inhibit practitioners from using the guidelines. Research supports the use of these guidelines and has also supported that there are common barriers to not using the guidelines. Evidence-based treatment of SSTIs is imperative to decreasing the rapidity of antibiotic resistance and practicing antibiotic stewardship.

The findings from this project demonstrated statistical significance. Practitioners do not have sufficient knowledge of CDC treatment guidelines, regional antibiograms, I\&D technique, or patient educational materials. This project supported the research finding that practitioners are confronted with several barriers in treating patients with SSTIs in the era of CA-MRSA. When provided with tools to address these barriers they are ready to treat CA-MRSA SSTIs according to evidence-based guidelines. The number of hits on the website supported use of information technology for future projects. The findings from this project support the implementation on a statewide level. 


\section{Attainment of Leadership Goals}

Conducting a research project as part of my DNP educational experience has provided enrichment to my leadership skills. The first step of searching the literature and formulating a systematic review gave me the confidence and skill to examine existing research and synthesize it for use in clinical practice. Applying the research to my clinical practice has allowed me to become an expert on the subject in Marion County with other practitioners consulting with me for direction on clinical treatment to improve their patients' outcomes.

During the development and implementation of this project, I had the privilege of working with leaders at FGH and other independent clinics. The insight gained from these leaders provided confidence during the project implementation. I deduced that leaders must have great leaders around them to be successful. I trust that as I become a leader in nursing, I will be able to mentor others as I have been mentored.

After completion of this capstone project, WVDHHR will be contacted for the purpose of working with them to launch the project statewide. The results of the systematic review have already been published, but opportunities will also be sought to publish the results of the entire project. The goal of publishing and sharing the results would be to encourage others to engage in evidence- based practice and to develop projects that would build off of this one. 
Appendix A - Capstone Budget

$\underline{\text { Estimated Cost } \quad \underline{\text { Actual }}}$

Webpage development

Weebly

Development Hours (10hrs X 30.00)
$\$ 39.95$

$\$ 300.00$
$\$ 39.95$

0.00

Educational Teachings

Lunches/Dinners
A. Fairmont Clinic
B. Manchin Clinic
C. Whitehall Clinic
D. Marion County Medical

0.00

0.00

$\$ 50.00$

75.00

$\$ 50.00$

25.00

0.00

0.00

Gas

$\$ 20.00$

25.00

Nursing CEUs/ CMEs

0.00

Cards-Follow-up/Thank you

$\$ 50.00$

$\$ 50.00$

Labor (5 hours X 30.00)

$\$ 150.00$

$\$ 150.00$

Evaluations
Paper
Photo Copies
Survey Monkey

$\$ 6.00$

0.00

0.00

0.00

\begin{tabular}{ll}
$0.00 \quad 0.00$ \\
\hline
\end{tabular}

$\underline{\text { Total }}$

$\$ 665$

$\$ 314$ 
Appendix B- CA-MRSA Website for Marion County, WV http://wvcamrsa.weebly.com CA-MRSA Skin and Soft Tissue Infections Marion County, WV 2012

\author{
Home \\ CDC Guidelines \\ Antibiogram \\ Incision and Drainage \\ Patient Education Tool
}

Evidenced Based Treatment Treatment of pediatric patients with community-acquired

methicillin resistant staphylococcus aureus (CA-MRSA) skin and soft tissue infections

(STTI) is a major

Figure 2 p. 2

challenge and concern in the global healthcare community. These infections are rapidly

becoming more prevalent and prevention of further antibiotic resistance is of paramount

importance. Primary health care providers need to know the most effective method of

treatment and control of CA-MRSA SSTIs in the pediatric population to achieve

resolution of infection, prevent adverse health outcomes, and limit spread of the

infection.

Appendix- MRSA: What you should know 
Appendix C- Patient/Family Education Tool Michigan Department of Health
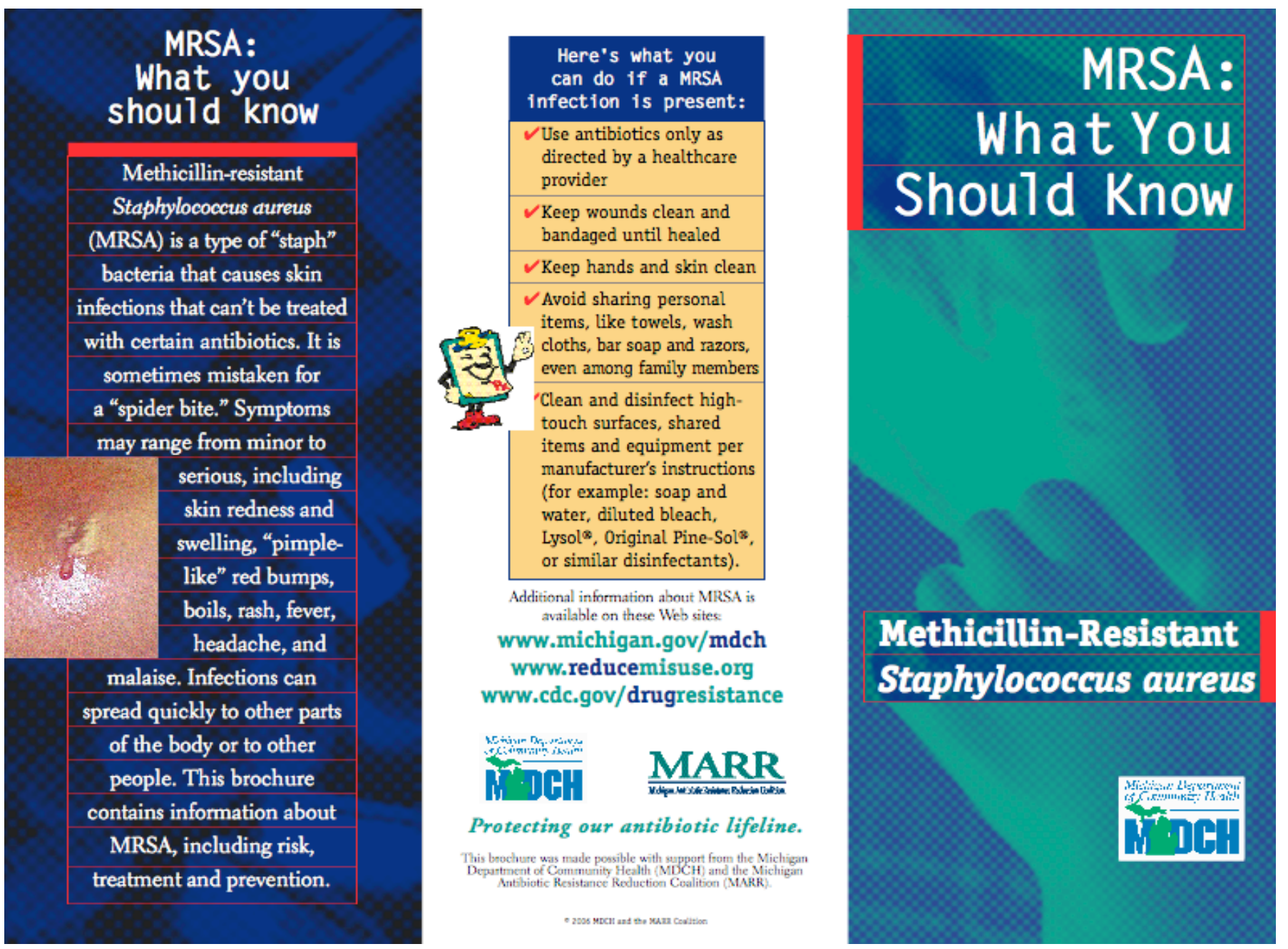


\section{Identify}

\section{Prevent}

\section{What is MRSA?}

Methicillin-resistant Staphylococcus aureus (MRSA) is a type of bacteria that causes

"staph" infections, ranging from minor skin

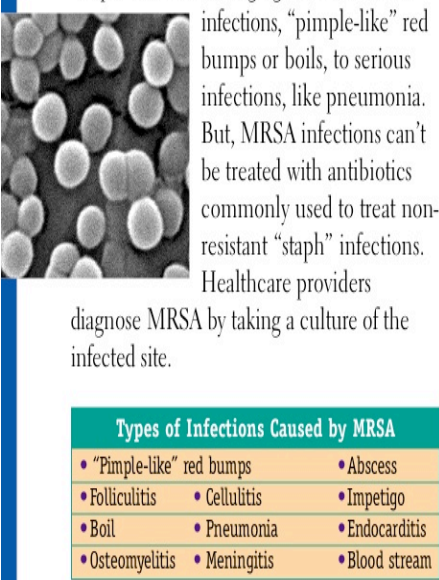

\section{How does MRSA spread?}

MRSA usually spreads from person to person through hands or close, skin-to-skin contact. Drainage from an infected wound can spread MRSA to other parts of the body or to other persons. We are all at risk for getting a MRSA infection, because MRSA can live on the skin and survive on some surfaces for prolonged periods of time.

\section{Risk Factors for MRSA}

- Close skin-to-skin contact

- Touching contaminated items and suffaces

- Crowded living conditions, like correctional

facilities, dormitonies, etc.

- Inadequate personal hygiene

- Openings in the skin, like cuts or abrasions

- Hospitalization, surgery or dialysis

- Indwelling medical devices, like a catheter or IV

- Living in a long-term care or rehabilitation facility

\section{How is MRSA treated?}

Antibiotics are not always needed to treat MRSA skin infections. Sometimes, a healthcare provider only needs to open and drain the wound. The wound should be cleaned often and kept covered to prevent spreading the infection.

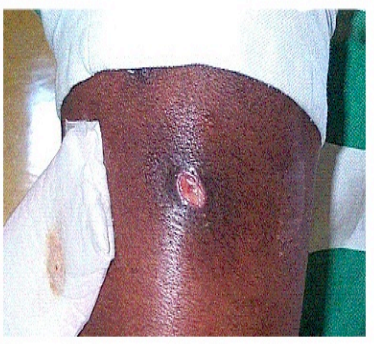

If wound draindge cannot be fully contained under a bandage, avoid close contact with others (work, school, sports activities) to prevent spreading. MRSA.

\section{Do antibiotics work on MRSA?}

When necessary, antibiotics may be used to treat MRSA infections. A healthcare provider should culture the infection to determine which antibiotic will work best.

Remember that antibiotics are "antibacterial," they do not work on viral infections, like colds or flu. It is very important to take antibiotics exactly as prescribed. Don't save them or share them with other people.

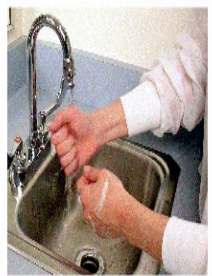

Cleon hands are the single most important factor in preventing the spread of dangerous germs. Wash hands with sodp and water, and scrub for at least 15 seconds.
How can I avoid getting or spreading MRSA?

Personal hygiene:

- Wash hands often with soap and water or use an alcohol-based hand sanitizer, especially atter touching wounds or bandages. - Do not share personal items, like towels, bar soap, wash cloths, razors, or clothing even among family members.

\section{Wound care:}

- Seek care immediately at first signs of infection (red, swollen, painful, warm, draining pus).

- Keep wounds clean and covered with a dry bandage, especially if the wound is draining.

- Follow your healthcare provider's instructions on proper wound care.

- Throw away soiled bandages.

- Avoid contact with other people's wounds or bandages.

Laundry:

- Wash clothes, towels and sheets in water with laundry detergent at holtest suitable temperature. Add bleach, if desired (check label instructionss. Dry in a dryer at hottest suitable temperature - do not "line dry."

Cleaning:

-Clean and disinfect high-touch or soiled suffaces (for example, door knobs and phones frecuently, and shared sports equipment between uses) according to item label cleaning instructions. Types of cleaning/disinfecting products include soap and water, diluted bleach, Lysol ${ }^{\circledR}$, Original Pine-Sol ${ }^{0}$. Follow label instructions for appropriate dilutions and contact times to be sure that surfaces are cleaned properly. 
Appendix D- Options for empiric outpatient treatment when MRSA is a consideration

\section{Outpatient ${ }^{\dagger}$ management of skin and soft tissue infections in the era of community- associated MRSA}

Patient presents with signs/symptoms of skin infection:

- Redness

- Swelling

- Warmth

- Pain/tenderness

- Complaint of "spider bite"

\section{YES}

Is the lesion purulent (i.e., are any of the following signs present)?

- Fluctuance-palpable fluid-filled cavity, movable, compressible

- Yellow or white center

- Central point or "head"

- Draining pus

- Possible to aspirate pus with needle and syringe

\section{YES}

1. Drain the lesion

2. Send wound drainage for culture and susceptibility testing

3. Advise patient on wound care and hygiene

4. Discuss follow-up plan with patient $\dagger$ For severe infections requiring inpatient management, consider consulting an infectious disease specialist.

$\ddagger$ Visit www.cdc.gov/mrsa for more information.

Abbreviations:

I\&D_incision and drainage

MRSA - methicillin-resistant $S$. aureus

SSTI_skin and soft tissue infection

Possible cellulitis without abscess:

- Provide antimicrobial therapy with coverage for Streptococcus spp. and/or other suspected pathogens

Maintain close follow-up

- Consider adding coverage for MRSA (if not provided initially), if patient does not respond severe local symptoms, 


\section{Options for empiric outpatient antimicrobial treatment of SSTIs when MRSA is a consideration*}

\begin{tabular}{|c|c|c|}
\hline Drug name & Considerations & Precautions** \\
\hline Clindamycin & $\begin{array}{l}\text { - FDA-approved to treat serious } \\
\text { infections due to } S \text {. aureus } \\
\text { D-zone test should be performed } \\
\text { to identify inducible clindamycin } \\
\text { resistance in erythromycin-resistant } \\
\text { isolates }\end{array}$ & $\begin{array}{l}\text { Clostridium difficile-associated } \\
\text { disease, while uncommon, } \\
\text { may occur more frequently in } \\
\text { association with clindamycin } \\
\text { compared to other agents. }\end{array}$ \\
\hline $\begin{array}{l}\text { Tetracyclines } \\
\text { Doxycycline } \\
\text { - Minocycline }\end{array}$ & $\begin{array}{l}\text { - Doxycycline is FDA-approved to treat } \\
\text { S. aureus skin infections. }\end{array}$ & $\begin{array}{l}\text { - Not recommended during } \\
\text { pregnancy. } \\
\text { - Not recommended for children } \\
\text { under the age of } 8 \text {. } \\
\text { Activity against group A strep- } \\
\text { tococcus, a common cause of } \\
\text { cellulitis, unknown. }\end{array}$ \\
\hline Trimethoprim-Sulfamethoxazole & $\begin{array}{l}\text { - Not FDA-approved to treat any } \\
\text { staphylococcal infection }\end{array}$ & $\begin{array}{l}\text { May not provide coverage } \\
\text { for group A streptococcus, a } \\
\text { common cause of cellulitis } \\
\text { Not recommended for women in } \\
\text { the third trimester of pregnancy. } \\
\text { Not recommended for infants } \\
\text { less than } 2 \text { months. }\end{array}$ \\
\hline Rifampin & $\begin{array}{l}\text { - Use only in combination with other } \\
\text { agents. }\end{array}$ & $\begin{array}{l}\text { Drug-drug interactions are } \\
\text { common. }\end{array}$ \\
\hline Linezolid & $\begin{array}{l}\text { - Consultation with an infectious } \\
\text { disease specialist is suggested. } \\
\text { FDA-approved to treat complicated } \\
\text { skin infections, including those } \\
\text { caused by MRSA. }\end{array}$ & $\begin{array}{l}\text { Has been associated with } \\
\text { myelosuppression, neuropathy } \\
\text { and lactic acidosis during } \\
\text { prolonged therapy. }\end{array}$ \\
\hline \multicolumn{3}{|c|}{$\begin{array}{l}\text { MRSA is resistant to all currently available beta-lactam agents (penicillins and cephalosporins) } \\
\text { - Fluoroquinolones (e.g., ciprofloxacin, levofloxacin) and macrolides (erythromycin, clarithromycin, azithromy- } \\
\text { cine) are not optimal for treatment of MRSA SSTIs because resistance is common or may develop rapidly. }\end{array}$} \\
\hline \multicolumn{3}{|c|}{$\begin{array}{l}\text { * Data from controlled clinical trials are needed to establish the comparative efficacy of these agents in treating } \\
\text { MRSA SSTIs. Patients with signs and symptoms of severe illness should be treated as inpatients. } \\
\text { ** Consult product labeling for a complete list of potential adverse effects associated with each agent. }\end{array}$} \\
\hline \multicolumn{3}{|l|}{ Role of decolonization } \\
\hline \multicolumn{3}{|c|}{$\begin{array}{l}\text { Regimens intended to eliminate MRSA colonization should not be used in patients with active infections. Decolo- } \\
\text { nization regimens may have a role in preventing recurrent infections, but more data are needed to establish their } \\
\text { efficacy and to identify optimal regimens for use in community settings. After treating active infections and rein- } \\
\text { forcing hygiene and appropriate wound care, consider consultation with an infectious disease specialist regarding } \\
\text { use of decolonization when there are recurrent infections in an individual patient or members of a household. }\end{array}$} \\
\hline
\end{tabular}


Appendix E- Antibiogram Fairmont General Hospital 2011

\section{Staph Aureus}

$\begin{array}{ll}\text { Trimeth/Sulfa } & 100 \% \\ \text { Tetracycline } & 98 \% \\ \text { Rifampin } & 100 \% \\ \text { Cefazolin } & 43 \% \\ \text { Clindamycin } & 61 \% \\ \text { Vancomycin } & 100 \% \\ \text { Oxacillin } & 43 \% \\ \text { Linezolid } & 100 \%\end{array}$


Appendix F. Outline of educational session for practitioners

A. Introduction

1. Purpose of session

2. Background and significance of CA-MRSA SSTIs

3. Statement of the Problem: The prevalence of pediatric communityacquired methicillin-resistant staphylococcus aureus (CA-MRSA) skin and soft tissue infections (SSTIs) have been well documented, yet evidence supporting treatment standards for short-and long-term resolution is equivocal. Treatment changes are paramount in the fight against CAMRSA and practitioners must follow the clinical practice guidelines and begin to utilize incision and drainage (I\&D) more frequently and antibiotics less frequently.

4. Literature review and synthesis

5. Project
a. Guiding theory
b. Population
c. Objectives
d. Committee
e. Timeline
f. Evaluation

B. PICO statement- What is the effect of a pilot program that educates practitioners with treatment guidelines, regional susceptibility data, and incision and drainage (I\&D) technique versus common treatment practices to increase practitioner's knowledge and utilization of evidence based guidelines in the treatment of pediatric CA-MRSA SSTI over a three-month period?

C. CDC guidelines for treatment of CA-MRSA SSTIs

a. Brief overview of guidelines

b. Common barriers to use of guidelines

D. Antibiogram for Marion County

a. Brief epidemiology

b. Review of antibiogram and prescribing 
E. Incision and Drainage

a. Technique

b. Barriers to use

F. Patient Education Tool

a. Michigan Antibiotic Resistance Reduction

b. Use of tool

G. Website

H. Interaction and Questions 
Appendix G- Pretest/Posttest

For the current project, the purpose of this test is to ascertain practice patterns of practitioners when treating for CA-MRSA skin and soft tissue infections (SSTIs) in Marion County, WV.

1. In what age group do most CA-MRSA skin and soft tissue infections (SSTIs) occur?
a. 1 month-19 years
b. 20-30 years
c. $40-60$ years
d. $70-90$ years

2. When treating a SSTI, you would provide empiric coverage for CA-MRSA if you know the prevalence in Marion County is greater than?
a. $5-10 \%$
b. $10-15 \%$
c. $15-20 \%$
d. $>20 \%$

3.In your experience what is current prevalence of CA-MRSA in Marion County?
a. $20-30 \%$
b. $31-40 \%$
c. $41-50 \%$
d. $51-60 \%$

5. While awaiting culture results, which antibiotic is an appropriate choice for an otherwise healthy 18 - year old male Marion County resident with a $6 \mathrm{~cm}$ single lesion abscess on his buttocks
a. Rocephin 

b. Doxycycline
c. Keflex
d. Augmentin

6. Which of the following complies with established treatment guidelines to treat uncomplicated CA-MRSA SSTIs?
a. I\&D plus doxycycline
b. I\&D alone
c. Bactrim without I\&D
d. I\&D plus vancomycin

7. When you are considering a diagnosis of an uncomplicated versus complicated SSTI, which one of the following criteria is least important?
a. age of patient
b. location of infection
c. occupation of patient
d. co- morbid conditions

8. When you consider the susceptibility data for Marion County, which of the following would be the best choice for outpatient treatment of a complicated SSTI?
a. Keflex
b. Bactrim
c. Clindamycin
d. Minocycline

11. After performing $I \& D$, what antibiotic may protect against subsequent infections for the outpatient?
A. Doxycycline
B. Bactrim 

C. Vancomycin
D. Ceftriaxone

13. Is I\&D part of your treatment regimen for those who present with a CA-MRSA skin and soft tissue infection? (Y/N)

14. If you answered "No" to question 13, which of the following acts as a barrier for you from performing I\&D? Circle all that apply
A. Do not perform I\&D frequently enough to feel comfortable with it.
B. Lack supplies for performing I\&D
C. Do not have time to perform I\&D
D. Prefer for prescribe antibiotics rather than perform I\&D 
Appendix H- Three month follow-up evaluation

For the current project, the purpose of this test is to ascertain practice patterns for the treatment of CA-MRSA skin and soft tissue infections (SSTIs) in Marion County, WV.

1. In the last three months, have you treated a patient for a CA-MRSA SSTIs (Yes/No)?

2. Did you use the website (http://wvcamrsa.weebly.com)? (yes/no)

IF YES:

Did it help to decrease some of the barriers... (yes/no)

Rate the helpfulness on a scale of 1 (not at all helpful) to 5 (very helpful) for each component:

Guidelines 12345

Susceptibility Data 12345

I\&D Video 12345

Patient Education Tool 12345

3. Are you currently following CDC guidelines? (yes/no/unsure

Did the educational session change your treatment regimen? (yes/no)

If not, why?

A. I was already treating in line with CDC guidelines.

B. I am continuing to use a treatment regimen I prefer over the CDC guidelines.

C. I still have barriers that prevent me from implementing CDC guidelines

4. In what age group do most CA-MRSA skin and soft tissue infections (SSTIs) occur?
a. 1 month-19 years
b. 20-30 years
c. $40-60$ years
d. $70-90$ years

5. When treating a SSTI, you would provide empiric coverage for CA-MRSA if you know the prevalence in Marion County is greater than 

a. $5-10 \%$
b. $10-15 \%$
c. $15-20 \%$
d. $>20 \%$

6.In your experience what is current prevalence of CA-MRSA in Marion County?
a. $20-30 \%$
b. $31-40 \%$
c. $41-50 \%$
d. $51-60 \%$

7. While awaiting culture results, which antibiotic is an appropriate choice for an otherwise healthy 18 - year old male Marion County resident with a $6 \mathrm{~cm}$ single lesion abscess on his buttocks
a. Rocephin
b. Doxycycline
c. Keflex
d. Augmentin

8. Which of the following complies with established treatment guidelines to treat uncomplicated CA-MRSA SSTIs?
a. I\&D plus doxycycline
b. I\&D alone
c. Bactrim without I\&D
d. I\&D plus vancomycin

9. When you are considering a diagnosis of an uncomplicated and/or complicated SSTIs, which one of the following criteria is least important?
a. age of patient
b. location of infection 

c. occupation of patient
d. co- morbid conditions

10. When you consider the susceptibility data for Marion County, which of the following would be the best choice for outpatient treatment of a complicated SSTI?
a. Keflex
b. Bactrim
c. Clindamycin
d. Minocycline

11. After performing I\&D, what antibiotic may protect against subsequent infections for the outpatient?
A. Doxycycline
B. Bactrim
C. Vancomycin
D. Ceftriaxone

12. Is I\&D part of your treatment regimen for those who present with a CA-MRSA skin and soft tissue infections? (Yes/No)

13. If you answered "No" to question 13, which of the following prevent you from performing I\&D? Circle all that apply
A. Do not perform I\&D enough to feel comfortable with it.
B. Lack supplies for performing I\&D
C. Do not have time to perform I\&D
D. Prefer for prescribe antibiotics rather than perform I\&D. 


\section{Appalachian Spring Dermatology roo village orive Suite 201 Cosmetic and Laser Surgery Center

Aaron Santmyire RN, FNP-BC, DNP Student

925 Dolly Terrace

LaVale, MD 21502

Dear Mr Santmyire

Appalachian Spring Dermatology is please to support your Capstone Proposal: Effect of a Pilot Program that Educates Primary Care Practitioners with Treatment Guidelines, Regional Susceptibility Data and I\&D in the Treatment of CA-MRSA SSTIs. Given the high prevalence of CA-MRSA in Marion County, we are pleased to offer our support for this project.

Please let me know how we can further assist you

Respectfully

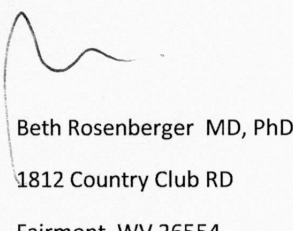

Fairmont, WV 26554 


\section{References}

Agency for Healthcare and Quality (2004). Literacy \& Health Outcomes. Retrieved from http://ahrq.hhs.gov/clinic/tp/littp.htm

AGREE Collaboration. (2006). Appraisal of Guidelines for Research \& Evaluation.

Retrieved September 12, 2010, from .

American Association of Colleges of Nursing (2006). The Essentials of Doctoral

Education for Advanced Practice. Washington, DC; AACN.

Andrade, S. E., Kahler, K. H., Frech, F., \& Chan, K. A. (2006). Methods for evaluation

of medication adherence and persistence using automated databases.

Pharmacoepidemiology and Drug Safety, 15(8), 565-74; discussion 575-7.

doi:10.1002/pds. 1230

Baker, C., Miller,L.,\& Weinstein, R. (2011) Current controversies: Containing MRSA in the days of blurring of community and hospital strains. Retrieved from http://www.medscape.org/viewarticle/734552

Baumann, B. M., Russo, C. J., Pavlik, D., Cassidy-Smith, T., Brown, N., Sacchetti, A., et al. (2011). Management of pediatric skin abscesses in pediatric, general academic 
and community emergency departments. The Western Journal of Emergency Medicine, 12(2), 159-167.

Barrett, F. F., McGehee, R. F.Jr, \& Finland, M. (1968). Methicillin-resistant staphylococcus aureus at Boston city hospital bacteriologic and epidemiologic observations. The New England Journal of Medicine, 279(9), 441-448. doi:10.1056/NEJM196808292790901

Centers for Disease Control. (2007). Options for empiric outpatient antimicrobial treatment of SSTIs when MRSA is a consideration. Retrieved November 10, 2010 from http://www.cdc.gov/mrsa/mrsa_initiative/skin_infection/PDF/provider/MRS A_ProviderBrochureF.pdf

Centers for Disease Control. (2010). MRSA Statistics. Retrieved from http://www.cdc.gov/mrsa/library/index.html

Chuck, E. A., Frazee, B. W., Lambert, L., \& McCabe, R. (2010). The benefit of empiric treatment for methicillin-resistant staphylococcus aureus. The Journal of Emergency Medicine, 38(5), 567-571. doi:10.1016/j.jemermed.2007.11.037

Coles, C. (2002). Developing professional judgment. The Journal of Continuing Education in Health Professions, 22, 3-10.

Daly, J. M., Levy, B. T., Ely, J. W., Swanson, K., Bergus, G. R., Jogerst, G. J., et al. (2011). Management of skin and soft tissue infections in community practice before 
and after implementing a "best practice" approach: An iowa research network (IRENE) intervention study. Journal of the American Board of Family Medicine : JABFM, 24(5), 524-533. doi:10.3122/jabfm.2011.05.110017

Duong, M., Markwell, S., Peter, J., \& Barenkamp, S. (2010). Randomized, controlled trial of antibiotics in the management of community-acquired skin abscesses in the pediatric patient. Annals of Emergency Medicine, 55(5), 401-407. doi:10.1016/j.annemergmed.2009.03.014

Fergie, J. E., \& Purcell, K. (2001). Community-acquired methicillin-resistant staphylococcus aureus infections in south texas children. The Pediatric Infectious Disease Journal, 20(9), 860-863.

Fridkin, S. K., Hageman, J. C., Morrison, M., Sanza, L. T., Como-Sabetti, K., Jernigan, J. A., et al. (2005). Methicillin-resistant staphylococcus aureus disease in three communities. The New England Journal of Medicine, 352(14), 1436-1444. doi:10.1056/NEJMoa043252

Gorwitz, R. J. (2008). Community-associated methicillin-resistant staphylococcus aureus: Epidemiology and update. The Pediatric Infectious Disease Journal, 27(10), 925926. doi:10.1097/INF.0b013e31818a3450

Hader, J.M., White, R., Lewis, S., Foreman, J.L., McDonald, P.W., \& Thompson, L.G. (2007). Doctors views of clinical practice guidelines: a qualitative exploration using innovation theory. Journal of Evaluation in Clinical Practice, 13(4), 601-606. 
Herold, B. C., Immergluck, L. C., Maranan, M. C., Lauderdale, D. S., Gaskin, R. E., Boyle-Vavra, S., et al. (1998). Community-acquired methicillin-resistant staphylococcus aureus in children with no identified predisposing risk. JAMA : The Journal of the American Medical Association, 279(8), 593-598.

Hersh, A. L., Cabana, M. D., Gonzales, R., Shenkin, B. N., \& Cho, C. S. (2009). Pediatricians' perspectives on the impact of MRSA in primary care: A qualitative study. BMC Pediatrics, 9, 27. doi:10.1186/1471-2431-9-27

Hyun, D. Y., Mason, E. O., Forbes, A., \& Kaplan, S. L. (2009). Trimethoprimsulfamethoxazole or clindamycin for treatment of community-acquired methicillinresistant staphylococcus aureus skin and soft tissue infections. The Pediatric Infectious Disease Journal, 28(1), 57-59. doi:10.1097/INF.0b013e3181826e5e

Klevens, R. M., Morrison, M. A., Nadle, J., Petit, S., Gershman, K., Ray, S., et al. (2007). Invasive methicillin-resistant staphylococcus aureus infections in the united states. JAMA : The Journal of the American Medical Association, 298(15), 1763-1771. doi:10.1001/jama.298.15.1763

Larrabee, J.H. (2009). Nurse to Nurse: Evidence-Based Practice. New York: McGrawHill.

Liu, C., Bayer, A., Cosgrove, S. E., Daum, R. S., Fridkin, S. K., Gorwitz, R. J., et al. (2011). Clinical practice guidelines by the infectious diseases society of america for 
the treatment of methicillin-resistant staphylococcus aureus infections in adults and children. Clinical Infectious Diseases : An Official Publication of the Infectious Diseases Society of America, 52(3), e18-55. doi:10.1093/cid/ciq146

McCaig, L. F., McDonald, L. C., Mandal, S., \& Jernigan, D. B. (2006). Staphylococcus aureus-associated skin and soft tissue infections in ambulatory care. Emerging Infectious Diseases, 12(11), 1715-1723.

Michigan Antibiotic Resistance Reduction Coalition. (2010). MRSA: What you should know. Retrieved from http://www.mi-marr.org/prov_materials.html.

National Institute of Health (2009). The History of Antimicrobial (Drug) Resistance.

Retrieved from http://www.niaid.nih.gov/topics/antimicrobialResistance/Understanding/Pages/histor y.aspx

New England Journal of Medicine. (Video file). Retrieved from http://www.youtube.com/watch?v=ov0aySQ839k

Newland, J. G., \& Kearns, G. L. (2008). Treatment strategies for methicillin-resistant staphylococcus aureus infections in pediatrics. Paediatric Drugs, 10(6), 367-378. doi:10.2165/0148581-200810060-00004

Parnes, B., Fernald, D., Coombs, L., Dealleaume, L., Brandt, E., Webster, B., et al. (2011). Improving the management of skin and soft tissue infections in primary 
care: A report from state networks of colorado ambulatory practices and partners (SNOCAP-USA) and the distributed ambulatory research in therapeutics network (DARTNet). Journal of the American Board of Family Medicine : JABFM, 24(5), 534-542. doi:10.3122/jabfm.2011.05.110018

Parse, R.R. (1992). Human becoming: Parse's theory of nursing. Nursing Science Quarterly, 5(1), 35-42.

Polit, D. E., \& Beck,T.C.(2011) Nursing research: Generating and assessing evidence for nursing practice. New York: Lippincott Williams \& Wilkins.

Rogers, Everett. (2003) Diffusion of Innovations (5th ed.). New York, Everett Rogers.

Ruhe, J. J., Smith, N., Bradsher, R. W., \& Menon, A. (2007). Community-onset methicillin-resistant staphylococcus aureus skin and soft-tissue infections: Impact of antimicrobial therapy on outcome. Clinical Infectious Diseases: An Official Publication of the Infectious Diseases Society of America, 44(6), 777-784. doi:10.1086/511872

Schmitz, G. R., Bruner, D., Pitotti, R., Olderog, C., Livengood, T., Williams, J., et al. (2010). Randomized controlled trial of trimethoprim-sulfamethoxazole for uncomplicated skin abscesses in patients at risk for community-associated methicillin-resistant staphylococcus aureus infection. Annals of Emergency Medicine, 56(3), 283-287. doi:10.1016/j.annemergmed.2010.03.002 
Scottish Intercollegiate Guidelines Network (2008). Critical appraisal: Notes and checklist. [on line]. Available www.sign.ac.uk/methodology/checklist.html.

Stevens, D. L., Bisno, A. L., Chambers, H. F., Everett, E. D., Dellinger, P., Goldstein, E. J., et al. (2005). Practice guidelines for the diagnosis and management of skin and soft-tissue infections. Clinical Infectious Diseases: An Official Publication of the Infectious Diseases Society of America, 41(10), 1373-1406. doi:10.1086/497143

Teng, C. S., Lo, W. T., Wang, S. R., Tseng, M. H., Chu, M. L., \& Wang, C. C. (2009). The role of antimicrobial therapy for treatment of uncomplicated skin and soft tissue infections from community-acquired methicillin-resistant staphylococcus aureus in children. Journal of Microbiology, Immunology, and Infection = Wei Mian Yu Gan Ran Za Zhi, 42(4), 324-328.

US Census Bureau (2009). State and County Quick Facts: Marion County, West Virginia Retrieved from http://quickfacts.census.gov/qfd/states/54/54049.html

West Virginia Department of Education (WVDE) (2010). Facts and Statistics. Retrieved from http://wvde.state.wv.us/abe/literacyestimates.htm

World Health Organization (2010) Antimicrobial resistance. Retrieved from http://www.who.int/patientsafety/implementation/amr/en/

Zaccagnini, M. \& White, K. (2011) The Doctor of Nursing Practice Essentials: A new module for Advanced Practice Nursing. Jones \& Bartlett, Mass. 